\title{
A review of the approaches to predict the ease of swallowing and post-swallow residues
}

\author{
M.Marconati ${ }^{\mathrm{a}}$, J.Engmann ${ }^{\mathrm{b}}$, A.Burbidge ${ }^{\mathrm{b}}$, V.Mathieu $^{\mathrm{c}}$, I.Souchon ${ }^{\mathrm{c}}$, \\ M.Ramaioli ${ }^{\mathrm{a}, *}$ \\ ${ }^{a}$ Department of Chemical and Process Engineering, Faculty of Engineering and Physical \\ Sciences, University of Surrey, Guildford, GU2 7XH, United Kingdom. \\ ${ }^{b}$ Nestlé Research Center, Vers-chez-les-Blanc 44, 1000 Lausanne 26, Switzerland. \\ ${ }^{c}$ UMR GMPA AgroParisTech, INRA, Université Paris-Saclay, 78850 Thiverval Grignon, \\ France.
}

\begin{abstract}
Background Swallowing is a complex physiological process transporting food from the mouth into the esophagus. Understanding how food properties condition flow, ease of swallowing and amount of post-swallow residues can support the design and development of novel products with improved texture and swallow-ability. Diagnostics allowed visualizing directly the effect of bolus consistency on flow, but complementary approaches are needed to speed up the pace of product innovation.

Scope and Approach This review summarizes the state of the art with respect to the in vitro and in silico approaches to predict the ease of swallowing, with an overview of the oral, pharyngeal and esophageal swallowing. Physical and computational models are discussed and compared, highlighting capabilities and limitations.

Key Findings and Conclusions In vitro and in silico experiments represent attractive complements to the in vivo investigations because they allow varying parameters independently, which is key to understand the effect of different food and drink properties and to adapting them to different needs. Two motor control strategies are commonly used, namely imposing displacements or stresses. These models have helped clarifying the role of bolus rheology in the oral phase of swallowing and the importance of salivary coating in the pharyngeal bolus flow. Few areas of improvements were identified: the use of more realistic geometries and mechanical properties representing the relevant tissues, of lubrication boundary conditions and of a wider variety of food boli. Further clinical studies should also focus on identifying the most realistic motor control strategy to mimic human swallowing.
\end{abstract}

\footnotetext{
*Corresponding author. Tel.: 00441483686579

Email address: m.ramaioli@surrey.ac.uk (M.Ramaioli )
}

Preprint submitted to Trends in Food Science $\&$ Technology 


\section{Introduction}

Difficulties with food manipulation and ingestion are increasingly observed in elderly and studies reveal that the incidence of swallowing disorders in nursing homes commonly reaches $40 \%$ of the total number of patients hospitalized (Cichero et al., 2017). Dysphagia profoundly deteriorates the quality of life, by strongly limiting the variety of food, drinks and oral solid medications that can be safely swallowed (Leonard and Kendall, 2008, Carnaby-Mann and Crary, 2005). Management of dysphagia requires a patient centered-approach considering a broad spectrum of compensatory techniques, such the adjustment of posture during eating, surgical interventions and, in the most extreme cases, 15 enteral feeding (Leonard and Kendall, 2008).

The mechanism of swallowing and its phases have long been studied in the medical literature (Groher, 2016). Precise timing and neurologic control is necessary to coordinate the complex series of mechanisms to transport the food bolus whilst protecting the airway against aspiration and penetration (Leonard and Kendall, 2008; Logemann, 1988).

In healthy individuals swallowing of solids and liquids represents an activity that is generally accomplished with limited effort. Food structure and after swallow feel are however paramount factors that drive product acceptance and preference (Chen and Engelen, 2012).

25 Over the past years clinical studies have revealed the paramount role of food structure and rheology in the perceived ease of swallowing, triggering the attention of a wide and heterogeneous community of researchers whose activity is well synthesized by the growing number of articles dealing with textural modifications in the management of dysphagia (Steele et al. 2014, Cichero et al., 2017.

30 Steele et al., 2015). A wide number of in vivo studies has focused in particular on the role of bolus rheology leading to the general conclusion that thicker solutions promote safer swallows at expense higher of post swallows residues in the oral and pharyngeal cavity (Steele et al., 2014, 2015, Leonard and Kendall, 2008, Clavé et al., 2006; Vilardell et al., 2016). The use of food thickeners has

35 long been proposed to support nutrition and hydration of dysphagic patients. The degree of food structure introducing heterogeneity was also studied in relation to the increase in the amount of time required for bolus preparation and swallowing (Laguna et al. 2016, Laguna and Sarkar, 2016). The optimal texture and rheology of structured products and thickened beverages is however

40 still lacking a sound mechanistic justification. Moreover, the interplay between bolus properties, tongue coordination and lubrication of the oral cavity is not quantitatively understood.

Classical techniques such as videofluoroscopy (VFSS), videoendoscopy (VESS) and manometry have extensively been used to study swallowing disorders (Steele,

45 2015). Recent advances in micro electronics have also allowed for less invasive in vivo measurements of parameters such as tongue pressure pattern and position during swallowing (Steele, 2015). Progress in medical imaging has also led to higher temporal and spatial resolution of MRI and x-ray computed tomography during swallowing (Engmann and Burbidge, 2013, Levine and Rubesin, 2017 
Nonetheless, sensory and clinical evaluation of swallowing do not always converge to consistent results due to the different methodologies and materials considered by different studies. The availability of alternative techniques to in vivo measurements could allow for a more detailed understanding of swallowing

55 with the aim of identifying classes of liquids as a function of their rheological properties. In vitro experiments and in silico, or computational, models could also provide active support during the design of clinical studies, aiming at tailoring food and drink properties to the specific needs of different classes of patients.

${ }_{60}$ The complexity of the swallowing process has called for in vitro and in silico simplifications both in terms of geometry, physiology and bolus properties. These simplifications have not always been critically discussed and have only rarely been validated against in vivo results.

The aim of this review is to outline the current state of the art in the computational and in vitro studies of human swallowing. The review is structured in three different sections. A brief introduction to the physiology of swallowing is initially presented, to illustrate the typical phases of swallowing and the context in which in vitro and in silico models ought to be developed. This is followed by a synthetic description of bolus and tissue properties to highlight their astound-

70 ing level of complexity. In vitro and in silico models are reviewed separately for the oral, pharyngeal and esophageal phases of swallowing. The last section comment critically the capabilities and the limitations of these in vitro and in silico models and suggests the future directions for their improvement.

\section{Key insights from in vivo studies}

75 2.1. The physiology of deglutition

Food oral processing begins in the oral cavity, a hollow space that extends from the lips anteriorly, to the palatoglossal arch posteriorly. The superior part of the oral cavity is characterized by a rigid structure composed of alveolar ridges, the hard palate, that posteriorly leads to the soft palate and terminates ${ }_{80}$ with the palatine uvola (Fig. 1). The tongue constitutes the inferior boundary of the oral cavity and has a paramount role in food oral processing as it is responsible for bolus manipulation and propulsion. The oral cavity posteriorly leads to the pharyngeal cavity via the Glossopalatal Junction (GPJ) that opens to the pharynx. The glottis separates the pharynx from the tracheal cartilages

and supports the vocal folds. The pharynx extends for a resting length of 12 to $14 \mathrm{~cm}$ and contracts, following the laryngeal elevation, to shorten the distance that the bolus has to travel during swallowing (Kou et al., 2017). Directly above the glottis sits a cartilaginous leaf-shaped structure, the epiglottis, that bends down in normal swallowing in order to guide the bolus downward to the esopha-

90 gus. This passive movement is initiated by the motion of the hyoid bone and is preceded by the swinging up of the soft palate that seals the nasopharynx. The pharynx terminates with the esophageal cricopharyngeal muscle, also referred 

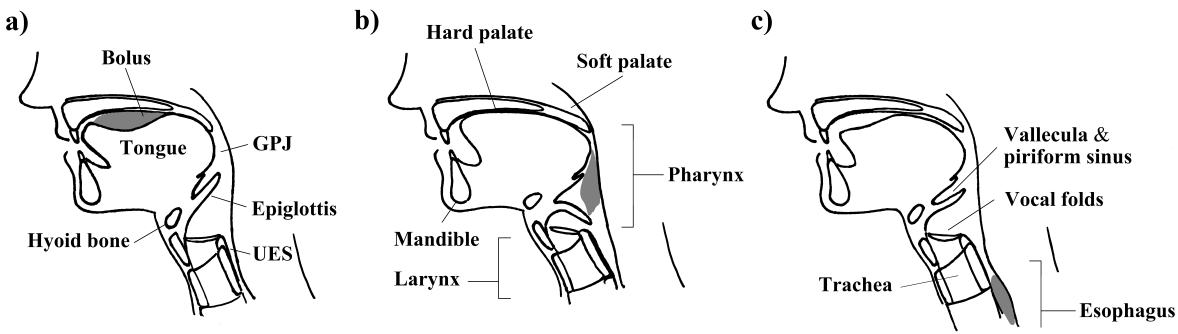

Figure 1: Schematic illustration of the three phases of swallowing: oral phase (a), pharyngeal phase (b) and esophageal phase (c).

to as Upper Esophageal Sphincter (UES) that leads to the esophagus. Here peristaltic contractions guide the bolus for a length of between 18 to $25 \mathrm{~cm}$ to 95 the stomach (Meyer et al., 1986). The swallowing process is articulated into subsequent stages starting with an oral preparatory step, and continuing with the oral, pharyngeal and esophageal phases (Fig. 1). These phases are interlinked and controlled by six cranial nerves, among which the the glossopharyngeal nerve is commonly believed to play a major role (Groher, 2016).

\subsection{Food bolus properties}

A complex series of destructive physical and chemical modifications characterize the transformation of foods into the shape of a flowable bolus (Chen, $2009,2012)$. The structural attributes of food dynamically evolve following the mechanical action of mastication, the wetting and lubricating action of saliva and the heat and mass transfer in the mouth within the duration of the oral preparatory phase of swallowing (Wang and Chen, 2017). Sensory stimuli are also greatly affected by the rate of aroma release which is influenced by the mass transfer coefficient and the chemical action of salivary enzymes (Adams and Taylor, 2012, Wang and Chen, 2017; Mosca and Chen, 2017).

Several in vitro models have been developed to study the the oral preparatory phase of swallowing (Peyron and Woda, 2016). These studies related the effort required for mastication of several model and real foods to the final particle size distribution. In vivo, the biting force depends on the mechanical properties of the chewed food. The number of chewing cycles was showed to be a function 115 of the material yield stress (Chen, 2009). The adaptation to the structural properties of the food matrix can be regarded as a force feedback loop induced by sensory stimuli. The challenge of fully modeling the path of solid food breakdown has been the subject of several reviews in the past and is still far from being fully addressed (Koç et al., 2013; Wang and Chen, 2017). The existence of a swallowing threshold in terms of bolus particle size, wettability or bolus cohesion is still debated (Koç et al., 2013, Wang and Chen, 2017; Chen, 2012).

Understanding bolus structure at the instant of swallow can help towards designing more effectively novel food and pharmaceutical products. Liquid foods 
are particularly relevant in the management of dysphagia, because they allow to address both the nutrition and the hydration of the patients.

Limiting the analysis to liquid formulations allows simplifying the problem due to the higher homogeneity and the shorter duration of the preparatory phase of swallowing. However, the bolus properties and the swallowing dynamics are affected by the unsteady heat transfer in mouth following the broad range of serving temperatures (Mosca and Chen, 2017). A recent review already highlighted how this aspect has not yet gained sufficient attention (Qazi and Stading, 2017).

While the structural attributes of solid and semisolid foods are often described in terms of force-displacement (Panouillé et al., 2016), rheology and tribology are also commonly used to characterize viscous and viscoelastic foods (Stokes, 2012b; Chen and Stokes, 2012).

Several studies have focused on the rheology of texture modified products used for dysphagia management emphasizing the more pronounced shear thinning behavior of gum based thickener with respect to starch based thickeners and their higher $\mathrm{pH}$ and temperature stability (Mackley et al., 2013, Hadde, 2017; Popa Nita et al., 2013, Funami et al., 2012). The need for categorization of the product nomenclature in respect of the desired product consistency led to the definitions of a few different standards (Cichero et al., 2017, Hanson, 2016). The consistency of qualitative descriptors of texture modified foods relies on ex145 tensive sensory tests and seldom allows for direct comparison between different products in terms of measurable rheological properties. In literature, the level of viscosity for liquid formulations is often referred to the classification published in 2002 by the National Dysphagia Diet (NDD) standardization initiative Sworn (2017). The guidelines there contained propose four different levels of thickened liquids based on shear viscosity measurements at the shear rate of 50 reciprocal seconds Hanson (2016). Following the NDD standardization, in 2009 similar guidelines were introduced in Japan with minor alterations to the viscosity ranges. Other countries have different legal requirements in relation to dysphagia thickeners, but mostly without explicitly referring to quantitative 155 values of viscosity or shear rates Hanson (2016). This lack of a worldwide agreement has led to the recent establishment of the International Dysphagia Diet Standardization Initiative (IDDSI), an organization created with the precise aim of developing an internationally recognized set of procedures and standards to manage dysphagia. The framework of IDDSI proposes an eight-level classification of the consistency of foods and drinks, thickened liquids being classified via the residual holdup in a standard $10 \mathrm{~mL}$ syringe discharging under gravity Cichero (2016). Although useful, these categorizations might call for an oversimplification of the rheological problem that excludes information about yield stress, shear thinning, viscoelasticity, and tixotropicity of liquid and semisolid products. Sensory studies comparing different food thickening agents report significant variations in terms of perceived viscosity and slickness (i.e. perceived slimy sensation) depending on the degree of shear thinning behavior (Matta et al., 2006, Hadde, 2017). Similarly, the viscoelastic properties of liquids are also expected to influence the perceived ease of swallow (Nystrom et al. 2015). 
In this regard, in silico methods have already highlighted that both shear and extensional flow occur as the bolus gets compressed between the tongue and the palate and during the pharyngeal phase of swallowing (Preciado-Méndez et al., 2017). To which extent bolus viscoelasticity might be important during swallowing is however still to be comprehensively investigated in vivo.

175 The properties of a liquid bolus can differ from those of the pre-swallowed liquid due to dilution with saliva, interaction of hydrocolloids with saliva, enzymatic transformations and temperature gradients. Furthermore the boundary conditions during bolus flow have to be carefully specified in order to account for salivary lubrication. In most in vitro and in silico literature food models are idealized either with Newtonian or simple power law fluids. Classical power law models represent well the steady shear rheology of Xanthan gum (XG) solutions over the range of shear rates expected during in vivo swallowing, but might be inadequate when considering starch based thickeners or other types of gum hydrocolloids (Martín-Alfonso et al., 2018). Newtonian models, on the other hand, only apply to water and sucrose syrups are certainly not representative of the common diet of dysphagic patients. Despite the variety of food tested during in vivo swallowing tasks, which also include barium impregnated cookies and rice, attempts to consider more complex foods in vitro are scarce. An in silico model for pharyngeal transport of a Hookean jelly was proposed

190 (Minizuma et al. 2009). Rice pudding was tested in vitro leading however to non physiologically realistic values of swallowing duration (Noh et al., 2012b). A study for the oral phase of swallowing in presence of suspended particles, as to mimic swallowing of solid oral dosage forms, was also published (Marconati et al. 2017b). In a recent follow-up article the same authors compared also the in vitro results obtained with multiparticulate formulations with the results of sensory tests (Marconati et al., 2018, Submitted).

\subsection{Mechanical properties of relevant tissues}

The biomechanical properties of the connective and epithelial tissue involved in the bolus transit have a paramount role in ensuring the correct functionality

200 of the swallowing process. Moreover, muscular tone and surface properties of the mucosa can significantly condition the efficiency of bolus transport. Previous studies aimed at characterizing the mechanical properties of oral and pharyngeal tissues by ex vivo tests in animals with similar digestive and associated metabolic processes to humans (Chen et al., 2015). These tests are typically carried out by 205 indentation, torsion and suction and aim of mapping the stress-strain behavior of the material with a constitutive law (Gerard et al. 2005). For sufficiently small applied stresses linear elasticity can be assumed leading to considerable simplifications in the description of the structural dynamics of the problem. In the case of isotropic and incompressible materials the problem is reduced to the determination of a single parameter represented by the Young's modulus.

However, the constitutive model that governs the stress-strain response of tissues can seldom be simplified with a constant elastic modulus due to the significant hardening followed by muscle activation (Chen et al., 2015; Weickenmeier et al., 2017). In the tongue, for instance values of Young modulus in 
contracted state were reported to exhibit more than 10-fold increase with respect to those measured in rest conditions (Duck, 1991). Aside of the increased stiffness due to muscular activation, a strain hardening response of physiological tissues is commonly observed at higher applied stresses. A correction to linear elasticity in these conditions is offered by hyperelastic models that describe the stress-strain behavior in terms of the derivative of the strain energy density.

An additional characteristic of the properties of muscular and epithelial tissue is their viscoelasticity that results into a time dependent mechanical response as a function of the history of deformation. Non invasive diagnostic tools such as Magnetic Resonance Elastography (MRE) have enabled in vivo quantification of the viscoelasticity of the tongue and the palate in the passive state during normal and assisted breathing. Chenet al. (Chen et al., 2015) reported values of shear modulus of around $2.5 \mathrm{kPa}$ for the tongue while slightly lower values for the palate. The magnitudes of the loss moduli were comparable, thus indicating the relatively high importance of the energy dissipation followed by tissue deformation. MRE was also used to quantify the anisotropy of muscular fibers that leads to tongue hardening in patients affected by Obstructive Sleep Apnoea (OSA) (Cheng et al. 2011). However, similar data are not available for cartilaginous structures such as the epiglottis and the larynx. Ex vivo measurements correlated the rigidity of connective tissues as a function of the collagen 235 quantity and the Young modulus of the epiglottis in rabbits was reported in the order of $0.25 \mathrm{MPa}$ for strains up to $20 \%$ (Naumann et al., 2002).

Concerning the assumption of tissue incompressibility, the data available suggest values of Poisson ratios close to 0.5 for predominantly muscular structures. Muscle tissue in fact is composed primarily of an aqueous liquid of negligible compressibility under normal physiological loads. Any change in one dimension due to muscle activation thereby results in a isochoric variation of the shape. Conversely, cartilaginous structures, such as the epiglottis and the larynx, exhibit a higher compressibility due to the more articulated structure of the matrix made up of collagen chains bounded by proteins. The assumption of 245 incompressibility applies to the tongue and the body of the pharynx, being predominantly comprised by multiple muscular tissues (Sokoloff, 2004, Kairaitis, 2010). The structure of these two organs is not supported by a skeletal system but the musculature itself acts as a support and an actuator for movement. A significant anisotropy stems from the directional orientation of muscular fibers within the tongue and the pharyngeal and esophageal constrictors. The deformability of the pharynx together with the properties of the mucosa have comprehensively been described in relation to the condition of pharyngeal collapse, observed in patients affected by OSA (Chen et al., 2015, Kairaitis, 2010).

Correctly capturing the structure of the oral mucosa lining the pharynx is particularly important in view of modeling its interaction with the bolus. The epithelial tissue is composed of a rigid non keratinized layer supported over highly vascularized connective tissues that provide a viscous damping effect, particularly important to protect palate and cheeks against wear during mastication. The mucosa is therefore a highly anisotropic and viscoelastic material whose mechanical properties have not yet been fully characterized. A recent 
review by Chen et al. (Chen et al. 2015) comprehensively examined the structure and mechanical models of pharyngeal mucosa reporting a broad spectrum of Young moduli reported in literature, spanning between 0.1 to $19 \mathrm{MPa}$.

\subsection{Salivary lubrication}

265 Saliva is a complex biological fluid that has an essential role in food oral processing (Schipper et al., 2007). The degree of oral lubrication significantly contributes to the oral perception of foods (Laguna and Sarkar, 2017a, 2016). The role of saliva is also instumental for bolus preparation before swallowing (Prinz and Lucas, 1995). Insufficient salivation (xerostomia) can lead to discomfort while swallowing together with a measurable increase in post swallow residues (Hamlet et al., 1997).

The influence of mucosa properties on the friction between bolus and oral cavity is greatly influenced by the degree of salivary lubrication of the epithelium.

275 Saliva coats the oral and pharyngeal mucosa with thickness that depends on the surface roughness of the underlying tissues (Carpenter, 2012). Several studies aimed at characterizing the thickness of the salivary layer leading to sparse results. Some authors have proposed indirect rough estimations in oral cavity, based on average measurements of saliva flow rate and of oral surface 280 areas, leading maximum values of up to 60-90 $\mu \mathrm{m}$ Collins and Dawes, 1987 . Watanabe and Dawes, 1990). More recently, measurements were carried out on normal subjects and on patients with salivary hypofunction, by determining the amount of saliva per unit area with paper strips (Pramanik et al., 2010). The salivary film thickness was thus shown to range from $5 \mu \mathrm{m}$ for the hard palate to $25 \mu \mathrm{m}$ for the tongue, consistently to the higher surface roughness of the lingual dorsum (Ranc et al. 2006).

The composition of saliva is mainly made up of water $(>99 \% \mathrm{w} / \mathrm{w})$ (Mosca and Chen, 2016, Schipper et al., 2007) while the physical and chemical properties of saliva are significantly affected by the concentration of mucins: large proteins

290 (0.5-20 MDa) composed of an amino acid backbone with chains of sugar residues (Chen, 2009, Carpenter, 2012). Entanglements between mucins gives saliva a mildly shear thinning property (Carpenter, 2012, Haward et al., 2011; Bongaerts et al. 2007, Schipper et al. 2007). Saliva is also characterized by a elongational viscosity. Ratios of elongational to shear viscosity higher than 100 were reported in literature (Haward et al. , 2011). The role of salivary lubrication in relation to food oral processing has been subject of an increasing number of studies in literature (Laguna and Sarkar, 2017b)

The tribological properties of saliva have been studied in relation to the sensation of creaminess, smoothness and astringency (Wang and Chen, 2017).

300 The coefficient of friction for saliva has been measured by sliding or rolling contact with metal identers. More recently, methods based on soft elastomeric substrates, as to include the deformability of biological tissues, have also been presented (Laguna and Sarkar, 2017a, Bongaerts et al., 2007).

Different studies however give often inconsistent results, as it was shown that the properties of human saliva greatly depended on the method of stimulation, 
$\mathrm{pH}$, donor and the way the biological samples are processed before experiments (Neyraud et al., 2012, Carpenter, 2012). The interaction of the salivary lubricating layer with soft tissues results in a further reduction of the friction coefficient that can be described coupling the lubrication theory with substrate deformation (Skotheim and Mahadevan, 2005). Values of friction coefficient two orders of magnitude lower than that obtained for water were reported for mechanically stimulated whole human saliva in the boundary lubrication layer (Bongaerts et al. 2007).

Measurements of wettability in the oral and pharyngeal mucosa are rarely attained in vivo and information on contact angles and adhesiveness still relies on ex vivo or animal data (Carpenter, 2012). The surface tension of mucous was described in relation to the magnitude of pressures required to separate mucosal surfaces that come into contact during airway collapse in patients affected by OSA (Kirkness et al. 2003). Further relevant studies considered the mucoadhesion in the esophagus for pharmacology and tablet design. In vitro experiments have been set up to quantify adhesion and detachment force of tablets against a simplified model of esophageal mucosa lined with artificial saliva (Smart et al., 2015). The esophageal mucosa is supported onto a sub frame of two layers of muscle orderly disposed in circular (skeletal musculature) and longitudinal

325 (smooth or visceral musculature) pattern. The muscular structure of the esophagus varies along its length. In particular, the aortic arch region demarcates the transition from a prevalent striated muscular structure to a smooth muscle region. Moreover, the transition between these zones is accompanied by a reduction in the intra-bolus pressure amplitude (Paterson, 2006, Ghosh, 2005).

The interactions between the bolus and the lubricated pharyngeal mucosa is critical to describe bolus flow during the peristaltic motion. Three situations have thus been envisaged in the literature depending on the type of food bolus considered (Pradal and Stokes, 2016): (i) a case with no significant interactions, where the salivary film keeps undisturbed lubricating properties, (ii) a case 335 where the interaction leads to the disruption of the salivary film and to an increase of the friction coefficient, and (iii) a case with synergistic interactions between some food compounds and the salivary film, leading to a decrease of the friction coefficient.

\section{In vitro and in silico models of human swallowing}

340 3.1. Swallowing motor control

Capturing the dynamics of swallowing in a model is a complex task because of the bolus field of motion and the interactions between the bolus, the mucosa, saliva and air. The sequence of movements and the spatial reconfiguration of the pharynx during swallowing ensure efficient bolus transport and full protection 345 of the airway against aspiration. The central nervous system is responsible for initiation and coordination of the swallowing process through the sensory feedback from the oral and the pharyngeal cavities (Jafari et al., 2003; Steele and Miller, 2010, Humbert and German, 2013). Both reflexive (or automic) 
and volitive (voluntary) behaviors concur to control swallowing (Ertekin, 2011). Wong et al. (Wong et al., 2017) showed that the trajectory of the hyoid bone and the extent of larynx elevation in different subjects are adapted to maximize airway protection. The pressures generated in the velopharynx were found to be dependent on the body position (Rosen et al., 2017). From an engineering perspective, four main alternative swallowing control scenarios can be envisaged:

355 -imposed displacements (with no control) -imposed forces (with no control) feed-forward control adapting the applied forces or displacements to the bolus characteristics perceived before the swallow -feedback control during swallowing, adapting forces or displacements

In vitro and in silico approaches to modeling swallowing have so far simplified the in vivo motor control either by considering an imposed kinematics (also known as displacement or strain control) or by prescribing stresses (force control). Modern diagnostics has made it reasonably easy to measure the displacement of the tissues involved in swallowing and this has induced some authors to impose the measured displacements in their in vitro and in silico models, assuming implicitly that these displacements are constant regardless of the properties of the fluid being swallowed. On the contrary, in a prescribed force (or stress) model, the bolus dynamics is directly influenced by the properties of the bolus being swallowed. Consistently with an imposed-stress flow, in vivo ultrasound observations by Mowlavi et al. showed an increase in oral transit time with 370 increasing viscosity (Mowlavi et al. 2016). Other in vivo studies also found different swallowing patterns when consuming solid foods compared to drinks (Steele and Miller, 2010). More complex, feed-forward or feedback control loops should also be considered. Some evidence supporting a feedback control was obtained applying anesthesia to the larynx, as this was found to induce laryngeal penetration, and tracheal aspiration (Steele and Miller, 2010, Sulica et al. 2002).

\subsection{In vitro and in silico models of the oral phase of swallowing}

The transport of a liquid bolus from the mouth to the pharyngeal cavity is preceded by the coordinated movement of tongue lips and cheeks muscles, necessary to hold the bolus preventing it from prematurely spilling into the pharynx and to separate the bolus into multiple sips (Burbidge et al., 2016). A quantitative understanding of the condition for liquid bolus spillage is of particular importance in patients with poor tongue coordination. In vivo studies have already proved how thicker fluids can promote sensory awareness and al-

385 low a better bolus control in the mouth. This last aspect has not yet been investigated in vitro, despite presenting some similarity with the classical, wellknown problem of sloshing. In the past, some anatomically sound applications of computational methods have been reported to simulate air flow through the oral cavity to study speech production and to investigate syndromes such as the OSA (Hofe and Moore, 2008, Buchaillard et al., 2009), while other studies have been dedicated to food breakage modeling in the oral cavity during mastication (Harrison and Cleary, 2014). 
Bolus containment in the oral cavity has been considered by Nicosia et al., using a two dimensional domain that replicates simple lingual gestures against rate resulted from the presence of slip at the boundary, in particular in case of the thinner liquid. These findings could indicate that the effect of salivary 
lubrication is significant when swallowing thick boli in vivo.

The studies above are however limited to the domain of Newtonian fluids, while most food products and texture modified foods used in the management and assessment of dysphagia exhibit a significantly more complex rheological behavior. Oral spreading of dairy products was considered both in vitro and in silico by Mossaz et al. (Mossaz et al., 2010). The authors investigated the

445 evolution of the spreading area of yogurt and cottage cheese, described through a Herschel-Bulkley model, between a parallel plate geometry to model the tongue compression against the hard palate. The model considered a constant speed squeezing of the bolus between the plates (between $5 \mathrm{~mm} / \mathrm{s}$ and $30 \mathrm{~mm} / \mathrm{s}$ ) to a prescribed strain whilst in-line monitoring the applied force. This was followed by a second phase of compression at constant force $(\mathrm{F}=1-10 \mathrm{~N})$. Coherently with in silico Finite Element simulations (FE), in vitro results show the lower the squeezing speed, the greater the spreading area at the same instantaneous compression force at imposed strains. Alterations to the surface finishing of the plates only lead to variations in the size of the spreading area during the constant force compression phase. The effect of partial slip at the wall was investigated in silico leading to a significant reduction in the compression force required to obtain the same bolus strain. However, both salivary lubrication and tissue elasticity remain unaddressed. Moreover the transition between the regime of imposed strain to imposed stress was not investigated in depth.

In an attempt to more comprehensively simulate the bolus transport in the oral phase of swallowing, Mackley et al. (Mackley et al., 2013) proposed an in vitro device, whose geometry was meant to approximate the tongue-induced peristaltic motion in the oropharyngeal cavity. The setup is conceptually similar to a peristaltic pump with the single degree of freedom found in the shaft 465 angular rotation. The liquid bolus is confined within a dialysis tube attached to the palate of the model while the tongue propulsion is modeled by the squeezing action of a roller driven by an external load. The bolus is therefore driven by imposing a force rather than a displacement, which leads to longer oral transit times with increasing bolus viscosity. The measured in vitro transit times 470 increased with increasing concentration of the thickener, above a threshold concentration of about $3 \%$, which corresponds to a Nectar-like consistency for the thickeners considered by the study (Mackley et al., 2013). This finding follows the experimental observation that thicker fluids flow less rapidly in the oropharynx, hence confirming the imposed-force approach considered by the 475 study. Moreover the authors also attempted to characterize the interaction between the bolus and epiglottis highlighting the occurrence of bolus splitting with increasing bolus viscosity. Meaningful direct comparison with in vivo images were not reported to validate the use of such a simple geometry. The region between the epiglottis and the esophagus is characterized by the presence of the ${ }_{480}$ vallecula and the piriform recesses. Recently proposed tomography techniques already proved that the flow of the bolus can unevenly spit in that region before merging at the entrance of the esophagus (Burbidge et al., 2016, Inamoto et al. 2011). The extent of intra-individual variability and head posture in relation to the bolus asymmetry in the oropharynx and laryngopharynx have however not 
yet been quantitatively assessed.

In a subsequent study, Hayoun et al. (Hayoun et al., 2015) improved the original design of Mackley et al. and proposed a theory capable of predicting the in vitro bolus velocity profiles from i) the viscosity of the Newtonian liquid tested and ii) the applied force to the roller. The authors were able to provide a qualitative comparison between in vitro experiments and in vivo ultrasound data when swallowing molasses. The authors categorized two regimes of bolus dynamics, one dominated by the system inertia and the other one driven by bolus viscosity. An extension of their study to non-Newtonian liquids considered the shear thinning behavior of aqueous solutions of a commercial thickener and provided a quantitative in vivo validation. (Mowlavi et al., 2016). Furthermore, the authors were able to prove the negligible effect of bolus density in the in vitro swallowing dynamics by comparing the results obtained with water based solutions ( $\mathrm{SG}=1$ ) against standard barium sulfate liquids used in videofluoroscopy study $(\mathrm{SG}=1.4)$. These studies therefore contributed significantly to bridge the gap between physical measurable properties (bolus volume, density and shear viscosity) with the bolus velocity, and therefore oral transit time, in a geometry that still retains a degree of similarity with the human oral cavity. Although these studies including an in vitro validation, the clinical data lacked measurement of the tongue pressures.

The tongue has a fundamental role in ensuring bolus containment and propulsion. Models of tongue pressure patterns during the oral phase of swallowing are available in literature and the mobility of the tongue has been the subject of a variety of in vivo and in vitro studies, not just limited to its action during swallowing. Talking robots have long been under development at Waseda university in Tokyo. The latest prototype was able to control the movement of a rubber tongue with seven degrees of freedom, three for the tip, two for the blade and the remaining two in the body (Fukui et al., 2009). Another mechanical device, inspired by the motion of the tongue, and actuated through tendons was developed by Kawamura and co-workers. But it was only recently that advances 515 in robotics allowed for the development of manipulators particularly suitable to replicate motion of unstructured tissues, able to compress, elongate, and bend in multiple directions simultaneously similarly to an octopus tentacle (Hughes et al. 2016). These characteristics, that started to get exploited for grippers and soft manipulators, are attractive when considering the design of an artificial tongue. Unlike conventional robots moved by imposed linear and angular displacements of rigid links, the kinematics of soft robots is governed by inflation and deflation of air chambers embedded in a support material characterized by high deformability. Despite the relative ease of manufacturing of soft manipulators the use of materials such as silicone, rubber, or other elastomeric polymers, does present significant challenges in terms of modeling the stress-strain behavior and the long term performance under fatigue (Hughes et al. 2016). These limitations partially explain the lack of applications of soft robotics specifically aiming at modeling the action of the human tongue, although with few exceptions. Recent studies focused on the development of a soft robotic tongue actuated under inflation of 6 internal air chambers embedded in a sandwich of 
a)
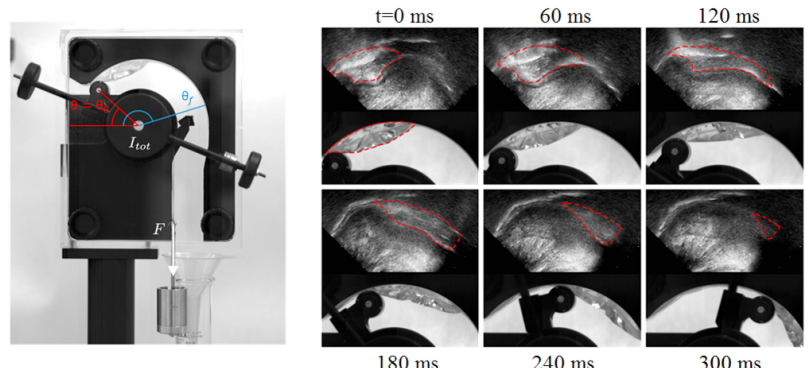

b)
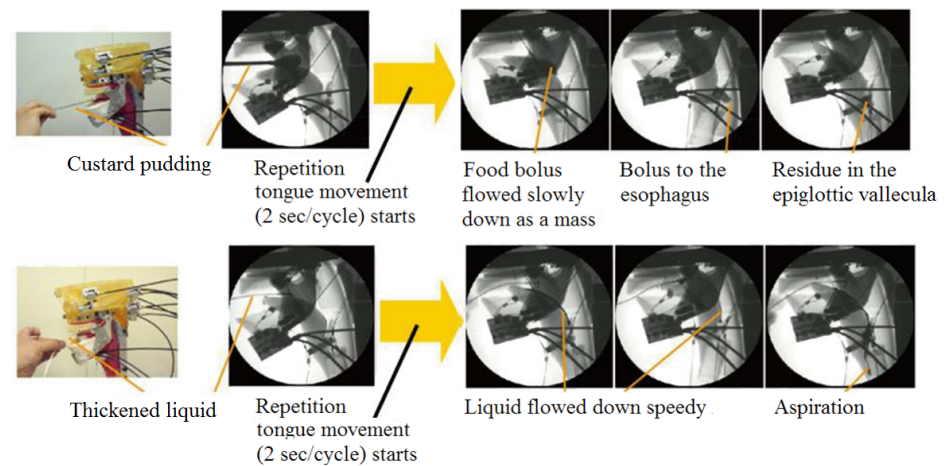

c)
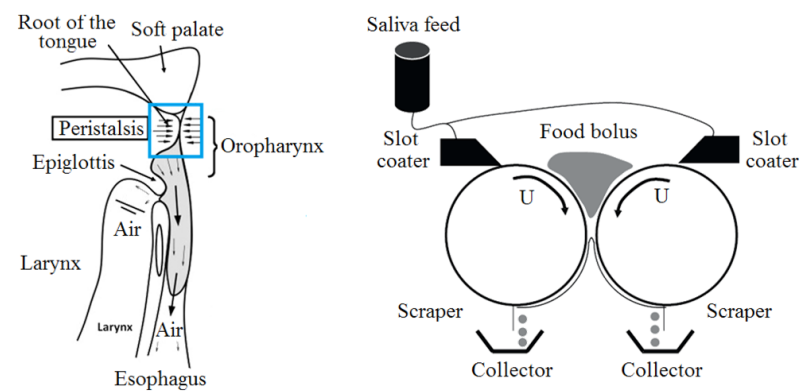

Figure 2: Examples of in vitro models of the oral and pharyngeal phases of swallowing. (a) Experiment, at imposed stresses, used to study the oral swallowing dynamics by Mowlavi et al.. Visual comparison between in vivo ultrasound images and in vitro tests with thick Newtonian boli was provided by the authors (Mowlavi et al. 2016). (b) Noh et al. replicated the oropharyngeal sequence of swallowing at imposed strains and used in vitro videofluoroscopy to assess the flow of liquid and semisolid boli (Noh et al. 2011). (c) Schematic of the pharyngeal peristalsis simulator, operating at imposed strains, developed by De Loubens et al. (de Loubens et al. 2010). Reprints with permission from the editor. 
elastomeric layers. The size of the prototype conserves the general proportions of the human tongue while simplifying its overall shape (Fig. 4 a). Separate control of the air pressure in the different chambers allows to replicate simple lingual gestures, such as tongue protrusion, bending and twist. Structural simulations, run using a commercial software, allowed to validate the in vitro kinematics by tracking the position of different markers on the tongue tip ( $\mathrm{Lu}$ et al. 2017). However, to date, multimodal bending, required to mimic tongue propulsion during the oral phase of swallowing, cannot yet be simulated by the device. Moreover, the dynamic response of the device was not investigated.

Recently, Redfearn and Hanson (Redfearn and Hanson, 2018) proposed an in vitro model to characterize the squeezing action of the tongue against the hard palate at the initiation of the oral phase of swallowing. This bidimensional model is operated imposing fixed displacements and monitoring both the pressure and velocity distribution along the bolus during the oral transit. The bolus velocities presented by Redfearn et al. are however lower than the in vivo measurements reported by Mowlavi et al. (Mowlavi et al. 2016).

A model experiment to study the force required to clear the bolus from the oral cavity to the pharynx through the GPJ was recently proposed by $\mathrm{Ng}$ et al., using a slip extrusion test in which model liquid and gels are extruded in a 550 plastic bag pulled through a pair of rollers at constant speed (Ng et al., 2017). The authors found a good correlation between measured deformation, slip resistance, and hardness and viscosity of the different samples. However, clinical implications of a similar testing method were not presented by the authors: the speed of bolus transport is limited to $20 \mathrm{~mm} / \mathrm{s}$ and the deformation of the plastic membrane used to mimic the oral cavity occurs symmetrically without considering the rigidity of the hard palate.

Structural and acoustic grid methods have been employed to study the motion of the tongue and speech production (Buchaillard et al. 2009), but these become inadequate and computationally expensive when dealing with swallow-

560 ing. Classical FE simulations based on a Lagrangian approach to represent the liquid domain cannot cope with very high deformations at interfaces, such as that observed during bolus flow. On the other hand, Eulerian methods used to simulate the air-liquid interface are of limited applicability, both due to the need for reliable transport equations to simulate the interface, and to numerical diffusion arising from the advection term in the momentum balance. Methods based on an ALE frameworks are potentially able to give useful insights in the computational model of bolus flow. However, they appear to be computationally expensive and still unable to fully model high deformation of the liquid domain (Kamiya et al., 2013).

Table 1: List of in vitro and in silico studies of the oral phase of swallowing.

\begin{tabular}{lllll}
\hline Reference & Bolus model & Measurement & Methodology & Conclusions \\
\hline Nicosia & $\begin{array}{l}\text { Newtonian liquids } \\
\eta=0.01,0.1 \text { and 1 } \\
\text { Pa.s. }\end{array}$ & $\begin{array}{l}\text { Condition for bo- } \\
\text { lus spillage under } \\
\text { prescribed lingual } \\
\text { gestures. }\end{array}$ & $\begin{array}{l}\text { 2D Fith imposed wallion } \\
\text { displacements. }\end{array}$ & $\begin{array}{l}\text { Thicker liquids avoid } \\
\text { premature spillage in } \\
\text { the pharynx under } \\
\text { sloshing. }\end{array}$ \\
\hline
\end{tabular}




\begin{tabular}{|c|c|c|c|c|}
\hline $\begin{array}{l}\text { Mossaz } \\
\text { et al. } 2010 \\
\end{array}$ & $\begin{array}{l}\text { Commercial yo- } \\
\text { gurt and cottage } \\
\text { cheese modeled as } \\
\text { Herschel-Bulkley } \\
\text { fluids. }\end{array}$ & $\begin{array}{l}\text { Bolus spreading area } \\
\text { in a squeezing flow } \\
\text { between two parallel } \\
\text { plates. }\end{array}$ & $\begin{array}{l}\text { In vitro model with } \\
\text { imposed strain and } \\
\text { stress. Numerical FE } \\
\text { simulation with im- } \\
\text { posed wall displace- } \\
\text { ments. }\end{array}$ & $\begin{array}{l}\text { Thicker boli spread } \\
\text { less and the spreading } \\
\text { area is inversely pro- } \\
\text { portional to the ap- } \\
\text { plied strain. }\end{array}$ \\
\hline \begin{tabular}{|l|} 
Nicosia \\
2013 \\
\end{tabular} & $\begin{array}{l}\text { Newtonian liquids } \\
\eta=0.01,0.1 \text { and } 1 \\
\text { Pa.s. }\end{array}$ & $\begin{array}{l}\text { Time required for oral } \\
\text { clearance and shear } \\
\text { rates as a function of } \\
\text { bolus density and vis- } \\
\text { cosity. }\end{array}$ & $\begin{array}{l}\text { Mathematical model } \\
\text { with imposed } \\
\text { stresses. }\end{array}$ & $\begin{array}{l}\text { Slip boundary con- } \\
\text { dition reduces the } \\
\text { time required for oral } \\
\text { clearance and shear } \\
\text { rates at the wall. }\end{array}$ \\
\hline \begin{tabular}{|l|} 
Hayoun \\
et al. 2015 \\
\end{tabular} & $\begin{array}{l}\text { Newtonian liquids } \\
\eta=0.006-1.2 \\
\text { Pa.s. }\end{array}$ & $\begin{array}{l}\text { Oral transit time and } \\
\text { velocity supported by } \\
\text { a predictive model. }\end{array}$ & $\begin{array}{l}\text { In vitro model with im- } \\
\text { posed stresses. }\end{array}$ & $\begin{array}{l}\text { Oral transit times in- } \\
\text { crease with bolus vol- } \\
\text { ume and viscosity. }\end{array}$ \\
\hline $\begin{array}{l}\text { Mowlavi } \\
\text { et al. } 2016 \\
\end{array}$ & $\begin{array}{l}\text { Newtonian liquids } \\
\eta=0.006-1.2 \text { Pa.s, } \\
\text { barium sulphate } \\
\text { and commer- } \\
\text { cial gum-based } \\
\text { thickener. }\end{array}$ & $\begin{array}{l}\text { Oral transit time and } \\
\text { velocity supported by } \\
\text { a predictive model. }\end{array}$ & $\begin{array}{l}\text { In vitro model with im- } \\
\text { posed stresses. }\end{array}$ & $\begin{array}{l}\text { Negligible inertial ef- } \\
\text { fects of bolus at high } \\
\text { viscosity. }\end{array}$ \\
\hline \begin{tabular}{|l} 
Marconati \\
et \\
$2017 \mathrm{a}$ \\
\end{tabular} & $\begin{array}{l}\text { Newtonian } \\
\text { uids } \eta=1.05 \\
\text { Pa.s } \\
\text { and } \eta=0.03 \text { Pa.s } \\
\text { as vehicles for } \\
\text { oral solid dosage } \\
\text { forms. }\end{array}$ & $\begin{array}{l}\text { Oral transit time, bo- } \\
\text { lus tail velocity and } \\
\text { relative position of } \\
\text { the tablets within the } \\
\text { bolus. }\end{array}$ & $\begin{array}{l}\text { In vitro model with im- } \\
\text { posed stresses. }\end{array}$ & $\begin{array}{l}\text { Tablet size and shape } \\
\text { affect oral transit } \\
\text { time. }\end{array}$ \\
\hline $\begin{array}{l}\text { Redfearn } \\
\text { and Hanson } \\
2018\end{array}$ & $\begin{array}{l}\text { Commercial } \\
\text { starch- and gum- } \\
\text { based thickeners } \\
\text { with } \eta=0.25 \text { Pa.s } \\
\text { at } 50 \text { reciprocal } \\
\text { seconds. }\end{array}$ & $\begin{array}{l}\text { Pressure and veloc- } \\
\text { ity distribution in a } \\
\text { squeezing flow. }\end{array}$ & $\begin{array}{l}\text { In vitro model with im- } \\
\text { posed displacements. }\end{array}$ & $\begin{array}{l}\text { Bolus flow is driven } \\
\text { by a pressure gra- } \\
\text { dient. Higher mean } \\
\text { velocities and lower } \\
\text { intrabolus pressures } \\
\text { found with gum-based } \\
\text { thickenes. }\end{array}$ \\
\hline$\frac{\sqrt{\mathrm{Ng}} \text { et al. }}{2017}$ & $\begin{array}{l}\text { Aqueous solutions } \\
\text { of } 1 \text { to } 2 \% \text { XG, } \\
\text { gelatin gels and } \\
\text { liquid particulate } \\
\text { systems. }\end{array}$ & $\begin{array}{l}\text { Force required to ex- } \\
\text { trude a bolus in a con- } \\
\text { verging geometry. }\end{array}$ & $\begin{array}{l}\text { In vitro model with im- } \\
\text { posed displacements. }\end{array}$ & $\begin{array}{l}\text { Lower extrusion } \\
\text { forces for the hydro- } \\
\text { colloids than gels and } \\
\text { particulate systems. }\end{array}$ \\
\hline
\end{tabular}

More recently, mesh-less methods have been employed to give a better visualization of fluid splashes and large transformations, that are not optimally captured with FE methods (Kamiya et al., 2013). The conceptual idea behind particle methods is that a fluid could be represented as an ensemble of calculation points (i.e. particles). Each fluid particle represents a small domain 575 of fluid containing parameters of local pressure and velocity. The calculation points, unlike classical mesh-based FE methods, are allowed to move in space as a result of their kinetic attributes. Following the trajectory of the particles in a Lagrangian framework suppresses the numerical instability caused by the presence of advection terms in the conservation equations, and gives a realis${ }_{580}$ tic representation of flow phenomena, especially in the case of splashing and sloshing (Kikuchi et al., 2015). The set of governing equations of fluid flow are described as the interaction between the reference particle and its neighbors, and thus the computational grid is not required.

By date, the two most widely used particle methods for flow characterization 585 are the Moving Particle Simulation (MPS) and the Smoothed Particle Hydrodynamics (SPH). Conceptually, both models share a similar structure, despite having appeared in two remarkably different frameworks.

The MPS method was originally developed by Koshizuka et al. Koshizuka, 2005 ) and is of relevant use to model free surfaces of incompressible fluids. The

590 fundamental equations of conservation of mass and momentum in the case of a non-compressible fluid are expressed in a Lagrangian form and are discretized as particle interaction models. Every particle of the model interacts only with 
surrounding particles within a certain radial distance. A kernel function is defined to account for neighbor interactions between particles and algebraic operations, defined on scalar and vectors, are approximated. The interfacial properties are considered using a continuum surface force model, which adds a force proportional to curvature of the interface on the free surface, calculated on two density functions.

Smoothed Particles Hydrodynamics ( $\mathrm{SPH})$ is a technique alternative to MPS that can be used for fluid dynamics simulations in presence of high surface deformations. Originally developed for astrophysics simulations, the SPH method has been used to simulate free surface flow and solid-laden liquid flows (Violeau and Rogers, 2016, Harting et al., 2014). In particular, SPH simulations have been extensively used in computer graphics to obtain realistic rendering of moving liquid interfaces. Like the MPS, the SPH is a Lagrangian mesh free method that discretizes the conservation equation using particles. Using both the SPH and MPS conceptions, any quantity of particle can be approximated by the direct summation of the relevant quantities of its neighboring particles. However, differently from the MPS algorithm, the SPH governing equations are ${ }_{610}$ that of compressible fluids and therefore require to be closed by an equation of state. Moreover the gradients and divergence terms of the conservation equations are computed through the differentiation of the kernel function that has therefore to be continuous, and is thereby characterized by a more complicated mathematical definition in respect of the MPS.

615 Ho et al. (Ho et al., 2014) performed a structural analysis of the tongue, palate, and oropharynx using a FE model implemented in ArtiSynth, an open source software specifically designed for biomechanical simulations (Lloyd et al. 2012). The organs were modeled based on MRI scans and the activation pattern of embedded muscular fibers was obtained from a previous study (Stavness et al. 2012). The authors first investigated the results of SPH simulations for a simple case of a Poiseuille flow in a tube and demonstrated that the initial arrangement of particles results in slight variation in the steady state solution (Ho et al., 2014). Then, they considered the fluid structure problem in the oropharyngeal cavity for which the fluid bolus consisted of just below 400

${ }_{625}$ particle elements, roughly corresponding to a simulated swallow of $1.3 \mathrm{~mL}$. The boundary conditions were expressed by dummy particles lining the surface of the solid organs, enforcing a non-penetration constraint. The authors did not properly justify their boundary condition choice, as the use of such boundary particles can allow slip in the tangential direction. The effect of gravity was not accounted for as the main aim of the researchers was to demonstrate that the SPH method is stable enough to withstand the squeezing flow deformations imposed by the motion of the tissues.

Later, Farazi et al. used the SPH to obtain a much more realistic visualization of a liquid bolus swallow (Farazi et al., 2015). The simulations made use 635 of more than 2500 particles simulating $20 \mathrm{~mL}$ of Newtonian fluids of two different consistencies: a water-like liquid $(\eta=0.001 \mathrm{~Pa} . \mathrm{s})$ and a nectar-thick fluid $(\eta=0.01$ Pa.s). A no-slip boundary condition was applied at the liquid-solid interface. The three dimensional model of the oropharyngeal cavity was built 
based on a symmetrical reconstruction of the anatomical structures from 2D videofluoroscopy images. The kinematics of the organs was modeled on VFSS which give the study clinically sound timings. The structural FE simulation was implemented with the same freeware software used by Ho et al.. SPH fluid and FE structure interaction is based on a one way coupling, even if the authors claimed the approach could be extended to consider a full two ways coupling.

${ }_{645}$ Unfortunately, the study does not provide any quantitative results aside from the qualitative conclusion that an increase in bolus viscosity results in slower dynamics. This leaves significant space for further validation of particle methods to geometries and boundary conditions relevant for the oral phase of swallowing.

\subsection{In vitro and in silico models of the pharyngeal phase of swallowing}

Significant rapid alterations to the bolus field of motion occur in the pharyngeal phase of swallowing. This begins with the bolus front passing through the GPJ and conventionally terminates when the bolus front enters the UES. This stage of swallowing is characterized by relevant and rapid alterations to the geometrical domain of the bolus field of motion, following the triggering of the complex series of mechanism held in place to protect the airway. The hyoid bone elevates shortening the pharynx and driving the down-fold of the epiglottis. At the same time pharyngeal musculature pushes the bolus downward with a further contribution generated by the pressure gradient that follows the relaxation of the UES. The speed of peristalsis was reported to be in the order of 660 approximately $15 \mathrm{~cm} / \mathrm{s}$ and the amplitude of the contraction waves in healthy subjects to be in the range between 13 and $20 \mathrm{kPa}$ (Mittal, 2012).

Table 2: List of in vitro and in silico studies of the pharyngeal phase of swallowing.

\begin{tabular}{|c|c|c|c|c|}
\hline Reference & Bolus model & Measurement & Methodology & Conclusions \\
\hline \begin{tabular}{|l|} 
Minizuma \\
et al. 2009 \\
\end{tabular} & $\begin{array}{l}\text { Jelly samples of } \\
\text { different hard- } \\
\text { ness. }\end{array}$ & $\begin{array}{l}\text { Bolus transit time } \\
\text { and position as a } \\
\text { function of time. }\end{array}$ & $\begin{array}{l}\text { 3D FE simulation } \\
\text { with imposed de- } \\
\text { formations of the } \\
\text { pharynx, prescribed } \\
\text { initial velocity of bo- } \\
\text { lus and wall friction. }\end{array}$ & $\begin{array}{l}\text { Soft boli deform more } \\
\text { in the region of the } \\
\text { epiglottis. }\end{array}$ \\
\hline $\begin{array}{l}\text { de Loubens } \\
\text { et al. 2010 }\end{array}$ & $\begin{array}{l}\text { Newtonian liquids } \\
\text { with } \eta \text { between } \\
0.026 \text { and } 0.4 \\
\text { Pa.s. }\end{array}$ & $\begin{array}{l}\text { Experimental and } \\
\text { theoretical values } \\
\text { of thickness and } \\
\text { composition of the } \\
\text { pharyngeal coating. }\end{array}$ & $\begin{array}{l}\text { Mathematical model } \\
\text { and in vitro experi- } \\
\text { ments. Imposed kine- } \\
\text { matics fixed geome- } \\
\text { try. }\end{array}$ & $\begin{array}{l}\text { The thickness of the } \\
\text { salivary layer and the } \\
\text { viscosity ratio with } \\
\text { the food bolus affect } \\
\text { the residue coating on } \\
\text { the pharyngeal mu- } \\
\text { cosa. }\end{array}$ \\
\hline 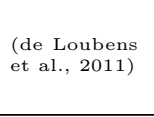 & $\begin{array}{l}\text { Newtonian liquids } \\
\text { with } \eta=0.005 \text { and } \\
\eta=0.05 \mathrm{~Pa} . \mathrm{s}\end{array}$ & $\begin{array}{l}\text { Values of thickness } \\
\text { and composition of } \\
\text { the pharyngeal coat- } \\
\text { ing. }\end{array}$ & $\begin{array}{l}\text { Mathematical model. } \\
\text { Imposed kinematic } \\
\text { constraint on peri- } \\
\text { staltic wave velocity. }\end{array}$ & $\begin{array}{l}\text { Velocity, viscosity ra- } \\
\text { tio and deformability } \\
\text { of the mucosa all in- } \\
\text { fluence the thickness } \\
\text { of the liquid coating. }\end{array}$ \\
\hline $\begin{array}{l}\text { Noh et al. } \\
2011\end{array}$ & $\begin{array}{l}\text { Barium sulfate } \\
\text { solutions, barium } \\
\text { custard pudding } \\
\text { and rice porridge. }\end{array}$ & $\begin{array}{l}\text { Transit times and } \\
\text { area of post-swallow } \\
\text { residues. }\end{array}$ & $\begin{array}{l}\text { In vitro model with im- } \\
\text { posed displacements. }\end{array}$ & $\begin{array}{l}\text { Thicker liquids leave } \\
\text { more residues in the } \\
\text { pharynx. Thin liquids } \\
\text { are aspirated. }\end{array}$ \\
\hline \begin{tabular}{|l|} 
Sonomura \\
et al. 2011 \\
\end{tabular} & $\begin{array}{l}\text { Water and two } \\
\text { shear thinning } \\
\text { power law liquids } \\
(\mathrm{K}=30 \text { and } 4.5, \\
\mathrm{n}=0.17 \text { and } 0.63 \\
\text { respectively). } \\
\text { Three volumes of } \\
\text { boli 2, } 5 \text { and } 10 \\
\text { mL. }\end{array}$ & $\begin{array}{l}\text { Bolus velocity and } \\
\text { conditions for bolus } \\
\text { aspiration in sim- } \\
\text { ulated swallowing } \\
\text { abnormalities. }\end{array}$ & $\begin{array}{l}\text { 3D FE simulation } \\
\text { with eulerian grid for } \\
\text { bolus flow. Imposed } \\
\text { motion of the pharyn- } \\
\text { geal walls and fixed } \\
\text { initial acceleration of } \\
\text { the bolus. }\end{array}$ & $\begin{array}{l}\text { Bolus velocity in the } \\
\text { pharynx increases } \\
\text { with its volume and } \\
\text { is not strongly de- } \\
\text { pendent on the liquid } \\
\text { rheology. Small boli } \\
\text { lead to post swallow } \\
\text { aspiration. }\end{array}$ \\
\hline
\end{tabular}




\begin{tabular}{|c|c|c|c|c|}
\hline \begin{tabular}{|l|} 
Kamiya \\
et al. 2013 \\
\end{tabular} & $\begin{array}{l}\text { Water } \quad \eta=0.001 \\
\text { Pa.s and } \mathrm{SG}=1 .\end{array}$ & $\begin{array}{l}\text { Leading edge position } \\
\text { of collapse of a water } \\
\text { column and visual as- } \\
\text { sessment of the swal- } \\
\text { lowing behavior in a } \\
2 \mathrm{D} \text { geometry. }\end{array}$ & $\begin{array}{l}\text { 3D MPS simulation } \\
\text { with imposed wall } \\
\text { displacements. }\end{array}$ & $\begin{array}{l}\text { Highlighted and tack- } \\
\text { led issues at mod- } \\
\text { eling structural me- } \\
\text { chanics with particle } \\
\text { methods. }\end{array}$ \\
\hline \begin{tabular}{|l|} 
Mackley \\
et al. 2013 \\
\end{tabular} & $\begin{array}{l}\text { Water, } 1 \% \text { XG } \\
\text { and two com- } \\
\text { mercial starch- } \\
\text { and gum-based } \\
\text { thickeners. }\end{array}$ & $\begin{array}{l}\text { Transit times and ef- } \\
\text { fect of the epiglottis. }\end{array}$ & $\begin{array}{l}\text { In vitro model with im- } \\
\text { posed force. }\end{array}$ & $\begin{array}{l}\text { Increased oral transit } \\
\text { times with viscosity } \\
\text { and increased bridg- } \\
\text { ing in proximity of } \\
\text { the model epiglottis. }\end{array}$ \\
\hline $\begin{array}{l}\text { Noh et al. } \\
2012 b)\end{array}$ & Dry swallow. & $\begin{array}{l}\text { Visual assessment by } \\
\text { practitioners. }\end{array}$ & $\begin{array}{l}\text { In vitro model with im- } \\
\text { posed displacements. }\end{array}$ & $\begin{array}{l}\text { Simulation of tongue } \\
\text { and mandible move- } \\
\text { ments for training of } \\
\text { medical doctors. }\end{array}$ \\
\hline $\begin{array}{l}\text { Ho et al. } \\
2014\end{array}$ & $\begin{array}{l}1.3 \mathrm{~mL} \text { of water- } \\
\text { thin and honey- } \\
\text { thick Newtonian } \\
\text { liquids }(\eta=0.001 \\
\text { and } 10 \text { Pa.s, } \\
\mathrm{SG}=1) \text {. }\end{array}$ & $\begin{array}{l}\text { Qualitative swallow- } \\
\text { ing behavior. }\end{array}$ & $\begin{array}{llr}3 \mathrm{D} & \mathrm{SPH} \text { numeri- } \\
\text { cal simulation } & \text { with } \\
\text { imposed wall } & \text { dis- } \\
\text { placements. }\end{array}$ & $\begin{array}{l}\text { SPH can handle liquid } \\
\text { structure coupling in } \\
\text { the pharynx. Water- } \\
\text { thin boli leave the } \\
\text { oral cavity with a } \\
\text { greater velocity. }\end{array}$ \\
\hline \begin{tabular}{|l|} 
Osada \\
et al. 2014 \\
\end{tabular} & $\begin{array}{lr}\text { Newtonian } & \text { liquid } \\
(\eta=0.0025 & \text { and } \\
\mathrm{SG}=1) \text { and a } \\
\text { power-law thick- } \\
\text { ener } \\
\mathrm{n}=0.276)\end{array}$ & $\begin{array}{l}\text { Velocity and force dis- } \\
\text { tribution in a control } \\
\text { region close to the } \\
\text { epiglottis. }\end{array}$ & $\begin{array}{l}\text { 3D MPS simulation } \\
\text { with imposed wall } \\
\text { displacements }\end{array}$ & $\begin{array}{l}\text { Thickened boli had } \\
\text { lower maximum ve- } \\
\text { locity in the pharynx } \\
\text { and flow with a nar- } \\
\text { rower velocity distri- } \\
\text { bution. }\end{array}$ \\
\hline 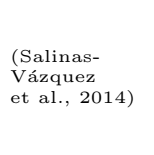 & $\begin{array}{lr}\text { Shear } & \text { thinning } \\
\text { liquid } & \mathrm{K}=20.5, \\
\mathrm{n}=0.39 & \text { and } \\
\mathrm{SG}=1.8 . & \end{array}$ & $\begin{array}{l}\text { Velocity and shear } \\
\text { rate in an axial } \\
\text { symmetric domain. }\end{array}$ & $\begin{array}{l}\text { Immersed boundary } \\
\text { axial-symmetric sim- } \\
\text { ulation with imposed } \\
\text { wall displacements } \\
\text { and inlet pressure. }\end{array}$ & $\begin{array}{l}\text { Channeling occurs at } \\
\text { the walls in for high } \\
\text { peristaltic wave pres- } \\
\text { sures. A combined } \\
\text { shear and extensional } \\
\text { flow is observed in the } \\
\text { pharynx. }\end{array}$ \\
\hline \begin{tabular}{|l|} 
Farazi \\
et al. 2015 \\
\end{tabular} & $\begin{array}{lrr}\text { Water } & \text { and } & \text { a } \\
\eta=0.01 & & \text { Pa.s } \\
\text { liquid. } & & \end{array}$ & $\begin{array}{l}\text { Numerical stability of } \\
\text { the coupling between } \\
\text { structural domain } \\
\text { and liquid domain. }\end{array}$ & $\begin{array}{l}\text { 3D SPH simulation } \\
\text { with imposed wall } \\
\text { displacements }\end{array}$ & $\begin{array}{l}\text { Water-like boli escape } \\
\text { the oral cavity with } \\
\text { greater velocity than } \\
\text { the nectar-like boli. }\end{array}$ \\
\hline \begin{tabular}{|l|} 
Kikuchi \\
et al. 2015 \\
\end{tabular} & Dry swallow. & $\begin{array}{lr}\text { Movement } & \text { of the } \\
\text { epiglottis } & \text { following } \\
\text { activation } & \text { pattern } \\
\text { of muscles } & \text { during } \\
\text { swallowing. } & \end{array}$ & $\begin{array}{l}\text { 3D MPS numeri- } \\
\text { cal simulation with } \\
\text { imposed wall dis- } \\
\text { placements. Effect of } \\
\text { epiglottis down-fold } \\
\text { was investigated. }\end{array}$ & $\begin{array}{l}\text { High friction coeffi- } \\
\text { cient between tissues } \\
\text { can limit the motion } \\
\text { of the epiglottis. }\end{array}$ \\
\hline $\begin{array}{l}\text { Hadde } \\
2017\end{array}$ & $\begin{array}{l}\text { Aqueous solutions } \\
\text { of a commercial } \\
\text { thickener } \eta=0.16- \\
0.95 \mathrm{~Pa} . \mathrm{s} \text { at } 50 \text { re- } \\
\text { ciprocal seconds. }\end{array}$ & $\begin{array}{l}\text { Bolus transit times } \\
\text { between two markers } \\
\text { in a vertical plane. }\end{array}$ & $\begin{array}{l}\text { In vitro model with im- } \\
\text { posed stresses. }\end{array}$ & $\begin{array}{l}\text { Longer pharyngeal } \\
\text { transit times and } \\
\text { higher pharyngeal } \\
\text { residues with increas- } \\
\text { ing bolus viscosity. }\end{array}$ \\
\hline $\begin{array}{l}\text { Ho et al. } \\
2017\end{array}$ & $\begin{array}{l}\text { Radio opaque } \\
\text { water-, nectar- } \\
\text { and honey-thick } \\
\text { solutions. }\end{array}$ & $\begin{array}{l}\text { Oral and pharyngeal } \\
\text { transit times, post } \\
\text { swallow residues and } \\
\text { visual analysis of the } \\
\text { bolus flow pattern } \\
\text { against in vivo data. }\end{array}$ & $\begin{array}{l}\text { 3D SPH simulation } \\
\text { with imposed wall } \\
\text { displacements. Kine- } \\
\text { matics obtained from } \\
\text { in vivo data. }\end{array}$ & $\begin{array}{l}\text { A no-slip boundary } \\
\text { condition better ap- } \\
\text { proximates in vivo } \\
\text { transit times. Post } \\
\text { swallow residues } \\
\text { increase with bolus } \\
\text { viscosity. }\end{array}$ \\
\hline \begin{tabular}{|l|} 
Kikuchi \\
et al. 2017 \\
\end{tabular} & $\begin{array}{l}\text { Newtonian liquid } \\
\eta=0.002 \mathrm{~Pa} . \mathrm{s}\end{array}$ & $\begin{array}{l}\text { Time variant particle } \\
\text { density in a control } \\
\text { region close to the } \\
\text { epiglottis and average } \\
\text { bolus velocity. }\end{array}$ & $\begin{array}{l}\text { 3D MPS simulation } \\
\text { with imposed wall } \\
\text { displacements }\end{array}$ & $\begin{array}{l}\text { Maximum bolus ve- } \\
\text { locity at the GPJ. } \\
\text { The shape of the } \\
\text { epiglottis is key to } \\
\text { avoid liquid penetra- } \\
\text { tion. }\end{array}$ \\
\hline \begin{tabular}{|l|} 
Preciado- \\
Mendez \\
et al. 2017 \\
\end{tabular} & $\begin{array}{lr}\text { Power law liq- } \\
\text { uid with } \\
\mathrm{n}=0.32 & \mathrm{~K}=11, \\
\mathrm{SG}=1.8 . & \end{array}$ & $\begin{array}{l}\text { Velocity and shear } \\
\text { rate in an axial } \\
\text { symmetric domain. }\end{array}$ & $\begin{array}{l}\text { Immersed boundary } \\
\text { axial-symmetric sim- } \\
\text { ulation with imposed } \\
\text { wall displacements. }\end{array}$ & $\begin{array}{l}\text { The bolus is subject } \\
\text { both to extensional } \\
\text { and elongational } \\
\text { stresses. }\end{array}$ \\
\hline \begin{tabular}{|l|} 
Mathieu \\
et al. 2018
\end{tabular} & $\begin{array}{l}\text { Water and glu- } \\
\text { cose solutions } \\
(\eta=0.0012-0.01- \\
0.057 \text { Pa.s and } \\
\mathrm{SG}=1-1.3)\end{array}$ & $\begin{array}{l}\text { In line measurement } \\
\text { of the thickness of } \\
\text { the coatings resulting } \\
\text { from bolus flow. }\end{array}$ & $\begin{array}{lr}\begin{array}{l}\text { In vitro } \\
\text { drodynamic }\end{array} & \text { mostohy- } \\
\text { model. } \\
\text { Combined } & \text { imposed } \\
\text { displacements } & \text { and } \\
\text { contact force. }\end{array}$ & $\begin{array}{l}\text { Mucosa stiffness, bo- } \\
\text { lus viscosity, salivary } \\
\text { flow rate and speed of } \\
\text { peristalsis affect the } \\
\text { thickness of pharyn- } \\
\text { geal coating. }\end{array}$ \\
\hline
\end{tabular}

The duration of the pharyngeal phase depends on the volume of the swallowed bolus and on the clinical condition of the patient. Power et al. measured average values of approximately 0.6 seconds in healthy subjects, while signifi- 
cantly longer transit times were observed in post stroke patients. In their review of temporal variability of events in recent dysphagia literature, Molfenter and Steele reported instead values spanning between 0.3 to $1.2 \mathrm{~s}$ (Molfenter and Steele, 2012).

The coordination of this series of events is of primary importance to ensure safe bolus transport, but undoubtedly poses significant challenges for in vitro simulations. Nonetheless a few experimental studies considering simplified geometries have been presented and can give quantitative insights of the bolus flow in the pharynx. A comprehensive list of the publications dealing with both in vitro and in silico models of the pharyngeal phase of swallowing is reported in Table 3.3.

Noh et al. (Noh et al., 2012a) have attempted to replicate realistically the physiology of the human oropharynx with the principal aim to develop a training tool for practitioners. The original prototype device was actuated by 16 servo motors through wire assemblies later replaced with motors. At the time of writing, the latest reported iteration of this mechanical device is the WKA-5 (Noh) et al. 2012b). This device has actively controlled degrees of freedom with torque sensors on each joint that can reproduce human muscle stiffness and respond to the external force of users. Sensors embedded in the tongue and pharynx allow to evaluate trainees' proficiency during assigned airway management tasks (such 685 as insertion of endoscopic probes and nasogastric feeding tubes).

The swallowing process with the previous generation simulator was successfully reproduced in vitro and assessed by videofluoroscopy images (Fig. 2 b). A range of barium impregnated foods (custard pudding and rice) were tested with that device in presence of artificial saliva to simulate the condition of the lingual mucosa (Noh et al. 2011). Preliminary experiments showed that for identically imposed displacement trajectories, there were significant differences in swallow efficacy. The authors reported that thicker barium solutions left more postswallow residues: $62 \%$ of the total initial swallowed volume remained in the oral cavity and above the epiglottis after competition of the swallowing mech${ }_{695}$ anism, compared to just $10 \%$ in case of non thickened barium sulfate solution. Moreover, the in vitro transit time required for swallowing of thick boli was considerably longer than that of thin liquids $(3.5 \mathrm{~s}$ versus $0.2 \mathrm{~s}$ for thin barium suspensions). The figures obtained for pharyngeal transit times are however still unrealistically long compared to any in vivo observation. This highlights the noticeable difficulties encountered while relying on the sole adaptation of the in vitro motor pattern to accommodate a few of the degrees of freedom that characterize the in vivo biomechanics of swallowing.

An in vitro study of pharyngeal phase of swallowing is ongoing at the Chalmers University of Technology (Gothenburg, Sweden). The model consists of a pumping system that approximates the geometry of the pharynx as a tube of constant elliptical cross section. The device has a movable flap to mimic the action of the epiglottis in order to consider the breathing-swallowing relationship. The flow of liquid bolus is monitored by a Doppler US to yield a complete spatial description of the flow field. Limited experimental results were published in (Qazi and Stading, 2017) and more results have become available 
only when this review was already in press ((Stading et al. 2019) $)$.

A more anatomically realistic model of the pharynx has been only recently presented by a French medical company active in the development and manufacturing of laryngeal implants (Debry et al., 2014; Tannock et al., 2017; Raguin et al. 2016). The in vitro model, used as a testing base for laryngeal prosthesis, replicates the motor pattern of the laryngeal sphincters, pharyngeal shortening and active epiglottis down-fold while also considering the activation and relaxation of the UES (Fujiso et al. 2018). A set of linear actuators are used to impose displacements to nodal points via steel wires: an approach that finds 720 roots in the swallowing robot by Noh et al.. The geometry of the model is based on a CT scan and the prototype is mold-casted in silicone rubber. Visual qualitative inspection and dynamic information from pressure transducers of the swallowing performance was investigated for thick liquids but the role of formulation rheology was not comprehensively investigated by the authors.

The pharyngeal phase of swallowing was also studied in vitro by Hadde who considered aqueous solutions of a commercial thickener in a range of shear viscosity at 50 reciprocal seconds spanning between 0.16 to 0.95 Pa.s (Hadde, 2017). The pharyngeal transit time was simply defined as the interval required for the bolus to cross two markers separated by a distance of $5 \mathrm{~cm}$ on a vertical 730 plane. The author showed that this pharyngeal time indicator was correlated with bolus apparent viscosity at 50 reciprocal seconds. The experiments demonstrated that the mass of residues in the oral cavity is directly proportional to the shear viscosity. Unrealistically long transit times were however recorded: increasing the value of shear viscosity from 0.46 to 0.80 Pa.s led to a 10 -fold 735 increase in the experimental oral transit times (from approx. $90 \mathrm{~ms}$ to more than $1 \mathrm{~s})$. Moreover experimental results also showed that decreasing the bolus volume (from 5 to $2 \mathrm{~mL}$ ) led to significantly higher oral transit times, a trend clearly not copied by any equivalent in vivo data. The author attributed the result to the neglected role of oral lubrication in vitro and suggested the intro-

740 duction of a lubricating fluid to better bridge in vivo observations with in vitro experiments (Hadde, 2017).

Some theoretical considerations and experimental methods were proposed to tackle the role of salivary coating in pharyngeal transport. In particular, De Loubens et al. focused on the thickness of bolus coating left behind by 745 pharyngeal peristalsis and proposed the use of lubrication theory to describe the variations of pharyngeal coatings with salivary flow rate. The authors idealized the most occluded region of the peristaltic wave during the pharyngeal peristalsis with a forward roll coating process at constant speed. The model considered a couple of counterotating rigid cylinders rotating at the tip velocity of $0.2 \mathrm{~m} / \mathrm{s}$. The two rollers are separated by a small adjustable gap where the fluid bolus gets squeezed (Fig. 2 c). The flow rate of thick glucose solutions $(\eta<0.5$ Pa.s) was found to be dependent upon the thickness of lubricating water layer (water) used to mimic saliva (de Loubens et al. 2010).

More recently, Mathieu et al. (Mathieu et al., 2018) investigated the elas755 tohydrodynamic problem of the pharyngeal phase of swallowing. The authors improved the the original in vitro setup of De Loubens et al. introducing a de- 
formable gelatin coating to mimic wettability and deformability of the pharyngeal mucosa. Furthermore a fixed contact force between the rollers was imposed in place of the fixed gap configuration originally considered by De Loubens et al.. Theoretical considerations of a similar elastohydrodynamic problem were provided by De Loubens et al. (de Loubens et al. 2011). It was found that varying the stiffness of the mucosa did not strongly impact on the measured bolus flow rate through the rollers. The thickness and the rate of dilution of the coatings were however found to be a decreasing function of bolus viscosity and 765 of the rotational velocity of the rollers. This conclusion was used to provide an interpretation to in vivo data of aroma release that indeed proved a decrease in measured aroma peak intensity with increased viscosity of the bolus (Doyennette et al. 2011). The viscoelasticity of saliva was however not accounted for, although qualitative observations suggest its importance (de Loubens et al., 2011). Similarly tests with shear thinning fluids were not performed, although potentially relevant, given the reported wide range of shear rates found in the gap between the rollers $\left(0-1000 s^{-1}\right)$.

Understanding the extent of shear rates during swallowing is of primary importance to design liquid and pureed products, as most food thickeners used 775 to manage dysphagia have a shear thinning rheological behavior. Meng et al. (Meng et al. 2005) used the finite volume approach to simulate the flow of Newtonian $(\eta=0.001$ and 0.150 Pa.s $)$ and power law $(K=2 n=0.7)$ fluids through a time variant axial symmetric geometrical domain of the pharynx. Time dependent radial displacements and pressure gradients were imposed to simulate opening of the UES and tongue applied pressure.

Maximum shear rates obtained from the simulation in the region proximal to the UES were of the order of 300 reciprocal seconds in case of water-thin liquids, whilst much lower values were obtained in case of thicker liquids. Furthermore, the authors showed that the time for a volume of $1 \mathrm{~mL}$ of bolus to flow increased 785 with an increase in the magnitude of the power law parameters (Meng et al. 2005).

Salinas-Vazquez et al. (Salinas-Vázquez et al., 2014) applied an immersed boundary method (IBM) to model the time variant shape of the pharynx of Meng et al.. IBM uses a fixed Eulerian mesh to solve the Navier-Stokes equations of the fluid domain whilst a non-stationary Lagrangian mesh models the fluid-solid boundaries within the Eulerian grid. Interpolation via a kernel function is used to exchange the dynamic information between the meshes to force the no-slip condition at the solid-liquid interface. The peristaltic movement was imposed using a fixed axial velocity of the pharynx surface, whilst the radial velocity was derived from the time variant positions of the wall surface used by Meng et al.. The effect of different pressure gradients was investigated. A non-uniform axial pressure distribution was needed for the simulation to correctly converge without the occurrence of reflux. The authors investigated the flow topology for a power law liquid indicating the existence of a narrow central 800 stream of relatively low shear rates ranging between 20 to 50 reciprocal seconds, axially surrounded by a region where the velocity gradients are as high as 200 reciprocal seconds. In case of non-Newtonian fluids, the authors thereby con- 
cluded that the liquid flow rate in close proximity to the walls was higher than that in the central region of the pharynx (Salinas-Vázquez et al., 2014).

Mizunuma et al. (Minizuma et al., 2009) first developed a three dimensional Lagrangian grid model of the flow of a semisolid bolus through a realistic 3D model of the oropharyngeal cavity. Tissues were simplified as isotropic materials with constant shear $(\mathrm{G})$ and bulk $(\mathrm{K})$ moduli taken from previous literature data (Minizuma et al. 2009). Salivary lubrication was accounted using a frictional 810 coefficient between the bolus and the structural mesh. Numerical results, not complemented with in vivo data, showed that, increasing the consistency of the semisolid bolus resulted in a reduction in its velocity, especially in proximity of the posterior wall of the pharynx. The motion models considered by the study were however overly simplified with discontinuous transitions between movements (Kikuchi et al. 2015). The work of Mizunuma et al. was then extended to liquid boli with different consistencies by Sonomura et al. (Sonomura et al., 2011). The authors conveyed a number of significant results out of their simulation study, some of them being directly compared with in vivo VFSS (Sonomura et al. 2011). Sonomura et al. were able to overcome some of the limitations of 820 the study by Mizunuma et al., by using a refined mesh made of solid elements, in place of shell elements, to better cope with large mesh deformations. Additionally, they made use of an Arbitrary Lagrangian Eulerian discretization method to better simulate the movement of a food bolus flow. The authors made an attempt to more realistically investigate the oral phase of swallowing by introducing a certain degree of mobility of the posterior dorsal part of the tongue. They studied some abnormal swallowing situations, with an epiglottis left in its upward position for the whole duration of the liquid swallow, or prematurely opened during the final moments of the pharyngeal phase (Sonomura et al. 2011). The way the anatomical structures were manipulated is essentially similar to what was already done by Mizunuma et al. with imposed displacements to specific points in the structural mesh, at fixed instants of time within the duration of the simulated swallowing $(0.8 \mathrm{~s})$. Differently from Mizunuma et al., the liquid bolus was initially held on the tongue and was subject to a constant body force acceleration of $2.2 \mathrm{~m} / \mathrm{s}^{2}$, a value not justified by the researchers, that 835 was maintained throughout the duration of the oral phase of swallowing. The dorsum of the tongue was then raised to squeeze the bolus into the oropharynx under a constant acceleration due to gravity. The computational model did not consider friction between the organ walls and the bolus. A simple slip velocity boundary condition was chosen to simulate the lubricating saliva layer covering the pharyngeal mucosa, in place of the frictional coefficient considered by Mizunuma et al.. This led to higher velocity measurements compared with contemporary in vivo ultrasound Doppler velocimetry (Hasegawa et al., 2005). Sonomura et al. compensated the discrepancy reducing the acceleration of gravity by a factor 3 (Sonomura et al., 2011). In silico simulations with the model 845 so corrected considered three different bolus volumes $(2,5$, and $10 \mathrm{~mL})$ and three level of consistency: water and two shear thinning fluids, representing the fluids used for VFSS by Nishinari et al. (Nishinari et al., 2011). Simulations in the case of normal swallowing showed a significant increase in bolus velocity 
in the pharyngeal phase whilst working with water. Conversely, both the ef-

fect of volume and rheology of the two non-Newtonian solutions did not leave a well-defined path in the simulations. However, in case of higher volumes of boli, the flow around the epiglottis was found to be relatively smooth and continuous with low overall residues on the vallecula and piriform sinus. The decrease in the volume of the bolus showed the possibility for an increase pooling that 355 might induce secondary liquid aspiration in case of abnormal swallows.

Despite the noticeable effort and the positive comparisons obtained between in silico results and in vivo VFSS and US Doppler velocimetry analyses, the model of Sonomura et al. still did not justify the choice of using a slip condition at the wall, artificially introduced to model saliva coating. Moreover the approach based on imposed displacements to the organs remains questionable when comparing the swallowing performance of liquid formulations of different rheological properties.

Moving Particle Simulation (MPS) was already described to simulate the swallowing action (Kamiya et al., 2013). Osada et al. used MPS to model swallowing of non-Newtonian fluids within in a three dimensional geometry obtained from MRI and CT scans. A power law approach was used to describe the rheological behavior of a commercial thickener, and showing narrower velocity distributions for the thickened boli than for water. Furthermore, the integration of particle transfer of momentum and pressure in the region of the epiglottis gave additional support to the theory that thickened fluids flow in a more regular pattern (Osada et al., 2014).

To improve the interactions between the liquid bolus and the walls, Kikuchi et al. verified the applicability of an Hamiltonian MPS method to describe hyper-elastic deformations and derived corresponding wall boundary conditions. The motion of organs is generated by imposing fixed displacements of internal groups of particles within the organs. The contact between the organ walls was modeled with penalty functions using metaballs as more comprehensively described by the authors themselves (Kikuchi et al., 2017). The structural coupling between organs was discussed with particular emphasis on the down

880 fold of the epiglottis. The friction coefficient was varied to represent that of a dry throat and a well disperse saliva coating. The authors presented a study to qualitatively compare simulations of a $6 \mathrm{~mL}$ water bolus with VFSS data (Kikuchi et al., 2017). A good agreement with in vivo observations was claimed by comparing the variations of brightness in the VFS images and the simulated bolus flow within the same control region close to the epiglottis. Values of shear rate as high as 300 reciprocal seconds were calculated, particularly at the entrance of the pharynx and of the esophagus. The authors found that the maximum velocity of the bolus is of the order of $0.5 \mathrm{~m} / \mathrm{s}$ and is reached at the end of the oral phase. Results showed also a temporary decrease in 890 bolus velocity at the beginning of the pharyngeal phase. However, the model neglects fluid-structure interaction and the overall system was assumed to be at constant pressure whilst in vivo measurements during swallowing show a gradient of pressures in the laryngopharynx following the laryngeal elevation and the relaxation of the UES (Butler et al., 2009). 
Finally, the role of salivary lubrication during the pharyngeal phase of swallowing was recently considered in the in silico study by Ho et al. (Ho et al., 2017). By confronting the in silico model with in vivo real time X-ray computed tomography the authors claimed a better similarity achieved while neglecting the role of salivary lubrication (Figure 3). This conclusion is however still based on an imposed kinematic to follow a pre-determined activation pattern of the organs, which oversimplifies the in vivo motor control.

Table 3: List of in vitro and in silico studies of the esophageal phase of swallowing.

\begin{tabular}{|c|c|c|c|c|}
\hline Reference & Bolus model & Measurement & Methodology & Conclusions \\
\hline $\begin{array}{l}\text { Misra and } \\
\text { Mait1 } 2012 \\
\end{array}$ & $\begin{array}{l}\text { Newtonian and } \\
\text { power law liquids } \\
\mathrm{n}=0.5,1 \text { and } 1.5\end{array}$ & $\begin{array}{l}\text { Pressure and veloc- } \\
\text { ity distribution in ax- } \\
\text { ial symmetric domain } \\
\text { with sinusoidal waves. }\end{array}$ & $\begin{array}{l}\text { Mathematical model. } \\
\text { Imposed wall dis- } \\
\text { placements. }\end{array}$ & $\begin{array}{l}\text { Shear thinning liquids } \\
\text { are more easily trans- } \\
\text { ported by peristalsis. }\end{array}$ \\
\hline \begin{tabular}{|l|} 
Tripathi \\
et al. 2013 \\
\end{tabular} & Jeffrey fluid & $\begin{array}{l}\text { Pressure velocity and } \\
\text { temperature distribu- } \\
\text { tion in axial symmet- } \\
\text { ric domain with sinu- } \\
\text { soidal waves. }\end{array}$ & $\begin{array}{l}\text { Mathematical model. } \\
\text { Imposed wall dis- } \\
\text { placements. }\end{array}$ & $\begin{array}{l}\text { Bolus transport and } \\
\text { thermal conduction is } \\
\text { affected by the vis- } \\
\text { coelastic properties of } \\
\text { the liquid bolus. }\end{array}$ \\
\hline \begin{tabular}{|l|} 
Dirven \\
et al. 2014 \\
\end{tabular} & Dry swallow. & $\begin{array}{l}\text { Description of the } \\
\text { synthesis and control } \\
\text { algorithm of a soft- } \\
\text { robotic peristaltic } \\
\text { actuator. }\end{array}$ & $\begin{array}{l}\text { Time imposed pres- } \\
\text { sure distribution to a } \\
\text { set of pneumatic actu- } \\
\text { ators. }\end{array}$ & $\begin{array}{l}\text { Feasibility study to } \\
\text { demonstrate the po- } \\
\text { tential of a soft ac- } \\
\text { tuator mimicking pri- } \\
\text { mary peristalsis. }\end{array}$ \\
\hline \begin{tabular}{|l|} 
Dirven \\
et \\
$2015 \mathrm{a}$ \\
\end{tabular} & Dry swallow. & $\begin{array}{l}\text { Measured peristaltic } \\
\text { wave trajectory by ar- } \\
\text { ticulography. }\end{array}$ & $\begin{array}{l}\text { In vitro model. Time } \\
\text { imposed pressure dis- } \\
\text { tribution to a set of } \\
\text { pneumatic actuators. }\end{array}$ & $\begin{array}{l}\text { Feasibility study to } \\
\text { demonstrate the po- } \\
\text { tential of a soft ac- } \\
\text { tuator mimicking pri- } \\
\text { mary peristalsis. }\end{array}$ \\
\hline \begin{tabular}{|l|} 
Dirven \\
et \\
$2015 \mathrm{~b}$ \\
\end{tabular} & 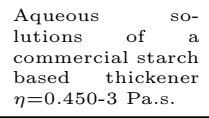 & $\begin{array}{l}\text { Measured pressure } \\
\text { profile during bolus } \\
\text { transit. }\end{array}$ & $\begin{array}{l}\text { In vitro model. Time } \\
\text { imposed pressure dis- } \\
\text { tribution to a set of } \\
\text { pneumatic actuators. }\end{array}$ & $\begin{array}{l}\text { Maximum intra-bolus } \\
\text { pressure increases } \\
\text { more than linearly } \\
\text { with bolus viscosity } \\
\text { measured at } 501 / \mathrm{s} \text {. }\end{array}$ \\
\hline 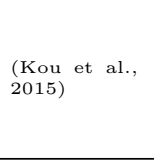 & $\begin{array}{l}\text { Newtonian bolus } \\
\eta=0.01 \text { Pa.s } \mathrm{V}=1 \\
\mathrm{~mL}\end{array}$ & $\begin{array}{l}\text { Pressure and ve- } \\
\text { locity distribution } \\
\text { from axial symmetric } \\
\text { model esophageal } \\
\text { peristalsis. }\end{array}$ & $\begin{array}{lr}\text { Immersed boundary } \\
\text { simulation. Imposed } \\
\text { longitudinal and } \\
\text { radial fiber displace- } \\
\text { ments embedded } \\
\text { in a multilayered } \\
\text { esophageal model. }\end{array}$ & $\begin{array}{l}\text { Coordination of cir- } \\
\text { cumferential and lon- } \\
\text { gitudinal muscles af- } \\
\text { fects bolus transport } \\
\text { and intra-bolus pres- } \\
\text { sure. }\end{array}$ \\
\hline \begin{tabular}{|l} 
Zhu et al. \\
2016
\end{tabular} & Dry swallow. & $\begin{array}{l}\text { Measured esophageal } \\
\text { deformation with im- } \\
\text { posed pressure distri- } \\
\text { bution. }\end{array}$ & $\begin{array}{l}\text { In vitro model. Time } \\
\text { imposed pressure dis- } \\
\text { tribution to the actu- } \\
\text { ators }\end{array}$ & $\begin{array}{l}\text { Development of a } \\
\text { control algorithm for } \\
\text { esophageal waveform. }\end{array}$ \\
\hline \begin{tabular}{|l|} 
Dirven \\
et al. 2017 \\
\end{tabular} & 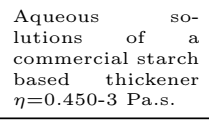 & $\begin{array}{l}\text { Measured pressure } \\
\text { profile during bolus } \\
\text { transit. }\end{array}$ & $\begin{array}{l}\text { In vitro model. Time } \\
\text { imposed pressure dis- } \\
\text { tribution to a set of } \\
\text { pneumatic actuators. }\end{array}$ & $\begin{array}{l}\text { Maximum intrabolus } \\
\text { pressure increases } \\
\text { with bolus viscosity. }\end{array}$ \\
\hline \begin{tabular}{|l} 
Kou et al. \\
2017
\end{tabular} & $\begin{array}{l}\text { Newtonian bolus } \\
\eta=0.01 \text { Pa.s } \mathrm{V}=1 \\
\mathrm{~mL}\end{array}$ & $\begin{array}{l}\text { Pressure and ve- } \\
\text { locity distribution } \\
\text { from axial symmetric } \\
\text { model esophageal } \\
\text { peristalsis. }\end{array}$ & $\begin{array}{lr}\text { Immersed } & \text { boundary } \\
\text { simulation. } & \text { Imposed } \\
\text { longitudinal } & \text { and } \\
\text { radial fiber } & \text { displace- } \\
\text { ments. } & \end{array}$ & $\begin{array}{l}\text { Stiffness of } \\
\text { esophageal mu- } \\
\text { cosa affects the bolus } \\
\text { transport. }\end{array}$ \\
\hline
\end{tabular}

\subsection{In vitro and in silico models of the esophageal phase of swallowing}

The final phase of swallowing initiates with the relaxation and opening of the UES that is followed by an increase in upper pharyngeal pressure (Butler et al. 905 2009) and a sudden reduction in laryngopharynx pressure. This is followed by the onset of a first peristaltic wave whose pressure amplitude ranges from 5 to 25 $\mathrm{kPa}$, depending on the subject gender, age, volume of bolus and type of probe used (Burbidge et al., 2016). In the esophagus ring-like progression of muscular contractions guide the bolus to the Lower Esophageal Sphincter (LES). The 


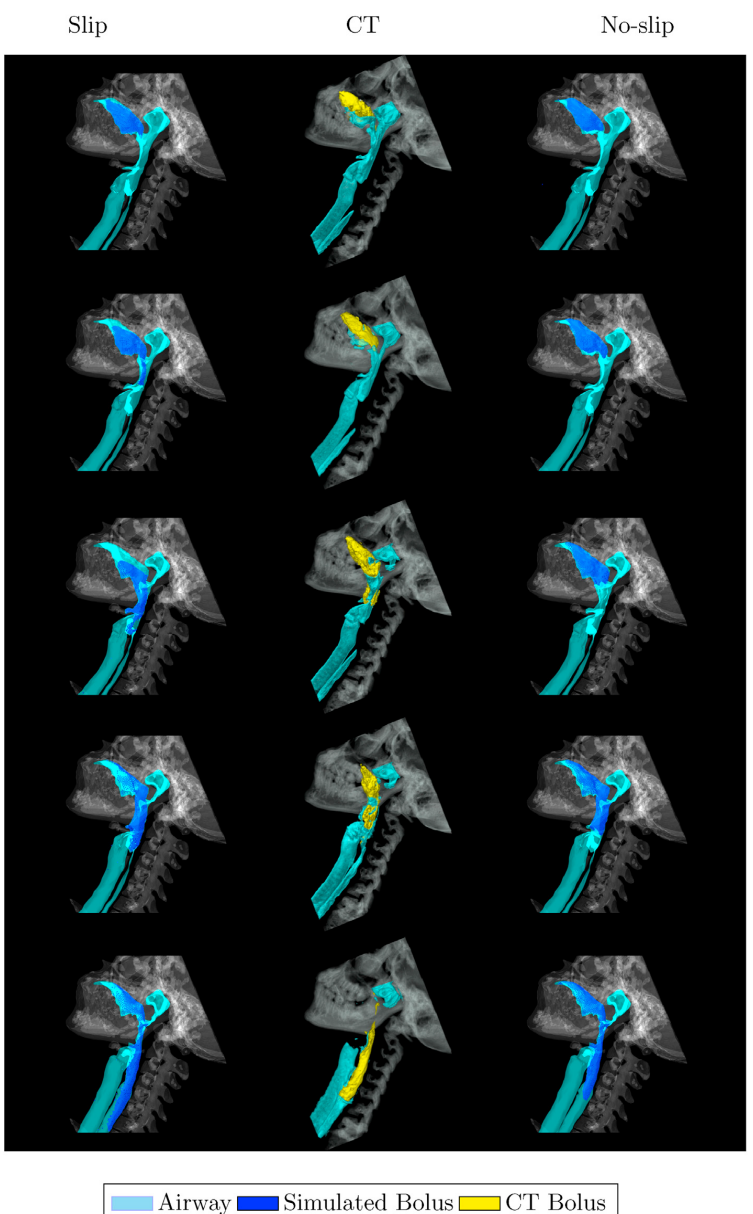

Figure 3: Visual comparison presented by Ho et al. to assess the effect of salivary lubrication (slip and no-slip) when simulating swallowing of a honey-thick bolus in a reclined position against in vivo CT data (Ho et al. 2017). Reprint with permission from the editor. 
speed of peristaltic contractions is limited to a few $\mathrm{cm} \mathrm{s}^{-1}$ and the velocity of the bolus is much reduced compared to the previous phases of swallowing. The duration of this phase is variable, depending on the viscosity and structure of the bolus.

In vivo studies with $\mathrm{VF}$ and manometry generated valuable kinematic and dynamic results on the esophageal peristalsis as a function of the bolus volume and viscosity (Paterson, 2006, Ghosh, 2005).

The closely related problem of peristaltic pumping of complex liquid and semi-solids has been subject of noticeable interest in literature. In vitro models have already been presented to simulate conceptually analogous problems, such as the flow of biological fluids. In these applications, peristalsis is induced by imposing wall displacements through rollers or pneumatic actuators (Jimenez Lozano, 2009).

Shape memory alloys, actuated by external electrical current were used to replicate basic features of esophageal peristalsis in animals (Watanabe et al. 2005). Chen et al. developed a pressure operated actuator capable of generating a periodical peristaltic wave to study the esophageal flow of a liquid bolus (Chen et al., 2012). The artificial esophagus is composed of a series of inflatable chambers made of a soft elastomer that are inflated and deflated accordingly (Fig. 4 b). In total, air pressure in 48 chambers could be manipulated to gen930 erate primary and secondary peristaltic contractions along the $20 \mathrm{~cm}$ length of the tube (Chen et al. 2012).

Manometry was used to evaluate the pressure within the transported bolus and the author observed a general nonlinear increase in intra-bolus pressure with increased bolus velocity and higher concentrations of the food thickener. Tests were run with aqueous solutions of a commercially available starch-based thickener with viscosity ranging between 0.1 and 5.4 Pa.s at the shear rate of 50 reciprocal seconds (Dirven et al., 2015a). Several publications focused on the issue of peristaltic wave shape and inflation control, but it is not clear whether the proposed model considered the different muscle activation patterns in the 940 distal zone of the esophagus, nor if the imposed radial displacement is a good assumption in respect of the longitudinal fiber contraction observed in vivo. Furthermore, the structure and wettability of the mucosa were not described by the authors. Accounting for the role of esophageal mucosa is a key to understand the tendency of some foods to stick in the esophagus. Delivery of solid oral dosage forms can both take advantage of mucoadhesion or be detrimental for the precise control of pharmacokinetics and bioavailability of the active principle. Tablets and capsules adhering to the pharyngeal and esophageal mucosa may lead to local inflammations and esophagitis (Ghosh, 2005). Few studies aimed at understanding how tablet shape and surface coating affect esophageal transit time and adhesion. In vivo models of esophageal mucosa have recently been proposed (Cook and Khutoryanskiy, 2015, Smart et al., 2015), but results so far have not considered the relevant challenges of drug therapy in dysphagic patients, such as the effect of co-administration with thickened liquids, nor how the physical alteration of capsules and tablets influence their residence time in the esophagus. 
a)
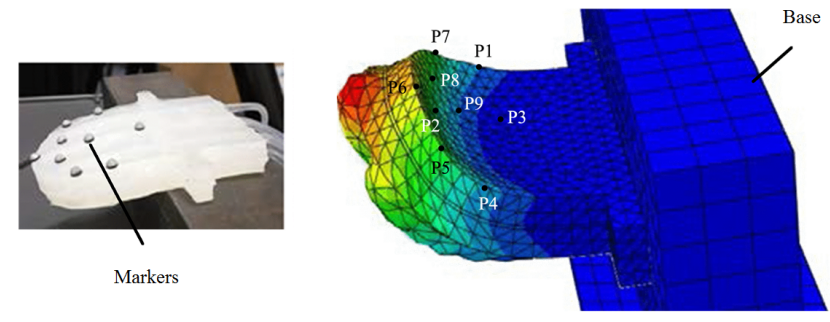

b)
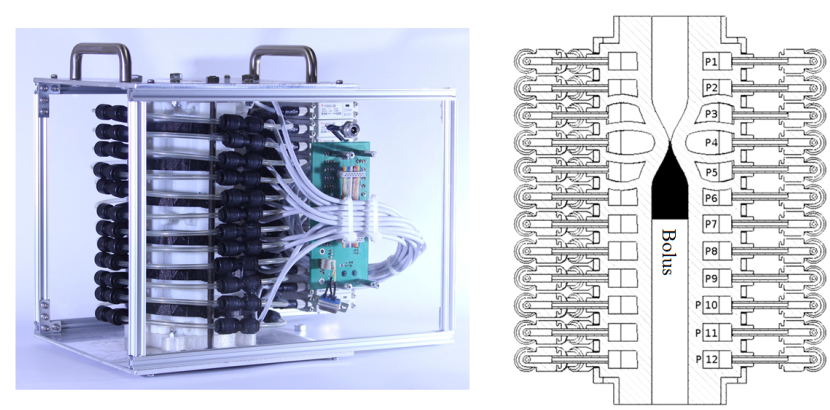

Figure 4: Soft robotics applications to swallowing. (a) Prototype and structural Finite Element (FE) simulation of a soft polydimethylsiloxane (PDMS) tongue proposed by Lu et al.. The organ can elongate and bend due to the differential stresses generated at the interface of upon inflation of embedded sets of air chambers (Lu et al. 2017). (b) Schematics of the swallowing robot used to simulate esophageal peristalsis by Dirven et al. (Dirven et al., 2017). Reprints with permission from the editor. 
Computational studies of the esophageal phase of swallowing have mainly considered the approximations used in the description of peristaltic flow. Analytical expressions for the stream function, axial velocity and pressure gradient could be obtained both for Newtonian and non-Newtonian fluids under the approximation that the amplitude of the peristaltic wave is much smaller than the wavelength and working at low Reynolds numbers. Shapiro et al. studied the peristaltic flow of a viscous fluid in an infinite tube by imposing a sinusoidal wall displacement (Shapiro et al., 1969). They performed the analysis under assumption of long wavelength and discussed the phenomena of liquid and trapping during peristalsis. Later Li and Brasseur studied the peristaltic flow of viscous fluid with constant viscosity through finite length tube and they have discussed the importance of finite length tube (Brasseur, 1987). The same authors extended the analysis to arbitrary wave shape and wavenumber in tubes of finite length showing that the extent of retrograde motion of fluid particles is much greater with single waves than with train waves ( $\mathrm{Li}$ and Brasseur, 1993). Peristaltic pumping of power law fluids have also been proposed showing a smoother intra-bolus pressure distribution as the flow index parameter $\mathrm{n}$ decreases, hence suggesting easier transport of pseudoplastic fluids (Misra and Pandey, 2001; Tripathi, 2011; Misra and Maiti, 2012). Viscoelastic

975 fluids, modeled through Jeffrey constitutive equation have also been proposed and a coupled fluid-dynamic and thermal simulation was presented by Tripathi et al. (Tripathi et al. 2013) under the hypothesis of small wavelength .

Computational models of peristalsis in the presence of suspended solids were proposed through the use of an immersed boundary method imposing prescribed displacements to the elastic boundaries (Fauci, 1992). Immersed boundary methods and particle methods have also recently been used to describe bolus transport in the gastrointestinal tract, as reviewed by (Cleary et al., 2015). A model of esophageal motion through circular and longitudinal muscle contractions was proposed by Kou et al. (Kou et al., 2015). The modeled esophagus was 985 considered as a multilayered deformable tube with embedded muscular fibers. however, in their study, the rheology of the bolus was simplified by considering a Newtonian behavior. Results for different activation pattern of the longitudinal and circumferential muscles show that coordination between lumen closure and esophageal shortening has an important effect on the intra-bolus pressure pattern. The role of mucosa stiffness in bolus transport was also highlighted in a following study by the same authors who, based on their simulations, speculate that a stiffened mucosa might lead to significantly back bolus transport (Kou et al. 2017).

\section{Conclusions and Future Research}

The growing interests towards swallowing and food oral processing has led to the introduction and development of a wide number of in vitro and in silico models. The mechanistic understanding derived from these tools provides explanations for a wide range of in vivo observations such as the evolution of tongue pressure with tongue position and the effect of the bolus viscosity on the aroma 
release from post-swallow residues. The valuable contribution of these swallowing model has also allowed to clarify the role of bolus density with respect to bolus viscosity. Moreover, comparing different liquid formulations proved the effectiveness of gum based thickeners in the management of dysphagia.

Despite these relevant results, both in vitro and in silico models still present significant limitations that need to be addressed. The common assumption of quasi two dimensional or axial symmetric flow remains hard to justify and a more accurate reconstruction of the region around the epiglottis seems advisable to correctly predict the quantity of post swallow residues and the conditions for bolus penetration. In terms of bolus models, most studies still consider 1010 simple viscous fluids with little insights into flow of thin liquids and viscoelastic fluids. The role of oral and pharyngeal lubrication is most often neglected, as well as the elastohydrodynamics of the tongue against the palate and of other tissues experiencing contacts. The physical properties of the epithelium itself have only been characterized in terms of mechanical deformability without sufficient attention to its wetting properties and their dependence on the salivary coating. While the role of salivary lubrication for liquid boli has not yet been comprehensively understood in vivo, studies on oral tribology could serve as a basis to underpin the potentiality of in vitro and in silico models for the oral and pharyngeal transport of semisolid boli. The incorporation of the salivary

1020 lubrication as a single friction coefficient or as a wall-slip velocity should be more appropriately justified and tailored to match relevant in vivo data.

Despite such limitations, in vitro and in silico models suggest interesting areas for future research. Most of the in vitro and in silico studies in literature impose displacements to the bolus, probably because these are easier to measure from in vivo diagnostics. Only few consider swallowing imposing stresses, despite some clinical evidence supporting this approach. More complex scenarios, such as a feed-forward or a feedback control have not been considered in in vitro and in silico models. Although some evidence already exists in support of these more complex scenarios, further clinial results are needed to better understand

${ }_{1030}$ the control strategy. Recent advances in medical instrumentation should also be used to further compare quantitatively in vivo data with models, further increasing the confidence in in vitro and in silico predictive approaches.

\section{Acknowledgments}

This study was funded by Nestlé Research.

\section{References}

Adams, S., Taylor, A. J., 2012. Oral Processing and Flavour Sensing Mechanisms. Food Oral Processing: Fundamentals of Eating and Sensory Perception, 177-202.

Bongaerts, J. H. H., Rossetti, D., Stokes, J. R., 2007. The Lubricating Properties of Human Whole Saliva. Tribology Letters 27 (3), 277-287. 
Brasseur, J. G., 1987. A fluid mechanical perspective on esophageal bolus transport. Dysphagia 2 (1), 32-39.

Buchaillard, S., Perrier, P., Payan, Y., 2009. A biomechanical model of cardinal vowel production: muscle activations and the impact of gravity on tongue positioning. The Journal of the Acoustical Society of America 126 (4), 20332051.

Burbidge, A. S., Cichero, J. A. Y., Engmann, J., Steele, C. M., 2016. " A Day in the Life of the Fluid Bolus ": An Introduction to Fluid Mechanics of the Oropharyngeal Phase of Swallowing with Particular Focus on Dysphagia. Appl. Rheol 26 (64525), 1-10.

Butler, S. G., Stuart, A., Castell, D., Russell, G. B., Koch, K., Kemp, S., 2009. Effects of Age, Gender, Bolus Condition, Viscosity, and Volume on Pharyngeal and Upper Esophageal Sphincter Pressure and Temporal Measurements During Swallowing. Journal of Speech Language and Hearing Research 52 (1), 240.

Carnaby-Mann, G., Crary, M., 2005. Pill Swallowing by Adults With Dysphagia. Archives of Otolaryngology-Head \& Neck Surgery 131 (11), 970.

Carpenter, G., 2012. Role of Saliva in the Oral Processing of Food. Food Oral Processing: Fundamentals of Eating and Sensory Perception, 45-60.

Chen, F., Dirven, S., Xu, W., Bronlund, J., Li, X., Pullan, A., 2012. Review of the swallowing system and process for a biologically mimicking swallowing robot. Mechatronics 22 (5), 556-567.

Chen, J., 2009. Food oral processing-A review. Food Hydrocolloids 23 (1), 1-25.

Chen, J., 2012. Bolus Formation and Swallowing. In: Food Oral Processing: 1065 Fundamentals of Eating and Sensory Perception. Wiley-Blackwell, Oxford, UK, pp. 139-156.

Chen, J., Ahmad, R., Li, W., Swain, M., Li, Q., 2015. Biomechanics of oral mucosa. Journal of The Royal Society Interface 12 (109), 20150325.

Chen, J., Engelen, L., 2012. Food Oral Processing. Wiley-Blackwell, Oxford, 1070 UK.

Chen, J., Stokes, J. R., 2012. Rheology and tribology: Two distinctive regimes of food texture sensation. Trends in Food Science and Technology 25 (1), $4-12$.

Cheng, S., Gandevia, S. C., Green, M., Sinkus, R., Bilston, L. E., 2011. Viscoelastic properties of the tongue and soft palate using MR elastography. Journal of Biomechanics 44 (3), 450-454.

Cichero, J. A. Y., 2016. Adjustment of Food Textural Properties for Elderly Patients. Journal of Texture Studies 47 (4), 277-283. 
Cichero, J. A. Y., Lam, P., Steele, C. M., Hanson, B., Chen, J., Dantas, R. O., Duivestein, J., Kayashita, J., Lecko, C., Murray, J., Pillay, M., Riquelme, L., Stanschus, S., 2017. Development of International Terminology and Definitions for Texture-Modified Foods and Thickened Fluids Used in Dysphagia Management: The IDDSI Framework. Dysphagia 32 (2), 293-314.

Clavé, P., De Kraa, M., Arreola, V., Girvent, M., Farré, R., Palomera, E., Serra-Prat, M., 2006. The effect of bolus viscosity on swallowing function in neurogenic dysphagia. Alimentary Pharmacology and Therapeutics 24 (9), $1385-1394$.

Cleary, P. W., Sinnott, M. D., Hari, B., Bakalis, S., Harrison, S. M., 2015. Modelling food digestion. Elsevier Ltd.

Collins, L., Dawes, C., 1987. The Surface Area of the Adult Human Mouth and Thickness of the Salivary Film Covering the Teeth and Oral Mucosa. Journal of Dental Research 66 (8), 1300-1302.

Cook, M. T., Khutoryanskiy, V. V., 2015. Mucoadhesion and mucosa-mimetic materials-A mini-review. International Journal of Pharmaceutics 495 (2), 991-998.

de Loubens, C., Magnin, A., Doyennette, M., Tréléa, I. C., Souchon, I., 2011. A biomechanical model of swallowing for understanding the influence of saliva and food bolus viscosity on flavor release. Journal of Theoretical Biology 280 (1), 180-188.

de Loubens, C., Magnin, A., Verin, E., Doyennette, M., Tréléa, I. C., Souchon, I., 2010. A lubrication analysis of pharyngeal peristalsis: Application to flavour release. Journal of Theoretical Biology 267 (3), 300-311.

Debry, C., Dupret-Bories, A., Vrana, N. E., Hemar, P., Lavalle, P., Schultz, P., 2014. Laryngeal replacement with an artificial larynx after total laryngectomy: The possibility of restoring larynx functionality in the future. Head \& Neck 36 (11), 1669-1673.

Dirven, S., Allen, J., Xu, W. P., Cheng, L. K., 2017. Soft-robotic esophageal swallowing as a clinically-inspired bolus rheometry technique. Measurement Science and Technology 28 (3), 035701.

Dirven, S., Xu, W., Cheng, L. K., 2015a. Sinusoidal Peristaltic Waves in Soft Actuator for Mimicry of Esophageal Swallowing. IEEE/ASME Transactions on Mechatronics 20 (3), 1331-1337.

Dirven, S., Xu, W., Cheng, L. K., Allen, J., 2015b. Biomimetic Investigation of Intrabolus Pressure Signatures by a Peristaltic Swallowing Robot. IEEE 
Dirven, S., Xu, W., Cheng, L. K., Bronlund, J., 2014. Soft-Robotic peristaltic pumping inspired by esophageal swallowing in man. In: Advances in Intelligent Systems and Computing. Vol. 274. pp. 473-482.

Doyennette, M., de Loubens, C., Déléris, I., Souchon, I., Trelea, I., 2011. Mechanisms explaining the role of viscosity and post-deglutitive pharyngeal residue on in vivo aroma release: A combined experimental and modeling study. Food Chemistry 128 (2), 380-390.

Duck, F., 1991. Physical Properties of Tissue. A Comprehensive Reference Book. Vol. 18. Academic Press.

1125 Engmann, J., Burbidge, A. S., 2013. Fluid mechanics of eating, swallowing and digestion - overview and perspectives. Food Funct. 4 (3), 443-447.

Ertekin, C., 2011. Voluntary Versus Spontaneous Swallowing in Man. Dysphagia $26(2), 183-192$.

Farazi, M. R., Martin-Harris, B., Harandi, N. M., Fels, S., Abugharbieh, R., 2015. A 3D dynamic biomechanical swallowing model for training and diagnosis of dysphagia. In: 2015 IEEE 12th International Symposium on Biomedical Imaging (ISBI). IEEE, pp. 1385-1388.

Fauci, L. J., 1992. Peristaltic pumping of solid particles. Computers Fluids $21(4), 583-598$.

1135 Fujiso, Y., Perrin, N., van der Giessen, J., Vrana, N. E., Neveu, F., Woisard, V., 2018. Swall-e: A robotic in-vitro simulation of pharyngeal swallowing. PLoSONE 13 (12).

Fukui, K., Ishikawa, Y., Ohno, K., Sakakibara, N., Honda, M., Takanishi, A., 2009. Three dimensional tongue with liquid sealing mechanism for improving

${ }_{1140}$ resonance on an anthropomorphic talking robot. In: 2009 IEEE/RSJ International Conference on Intelligent Robots and Systems, IROS 2009. IEEE, pp. 5456-5462.

Funami, T., Ishihara, S., Nakauma, M., Kohyama, K., Nishinari, K., 2012. Texture design for products using food hydrocolloids. Food Hydrocolloids $1145 \quad 26(2), 412-420$.

Gerard, J. M., Ohayon, J., Luboz, V., Perrier, P., Payan, Y., 2005. Non-linear elastic properties of the lingual and facial tissues assessed by indentation technique: Application to the biomechanics of speech production. Medical Engineering and Physics 27 (10), 884-892.

Ghosh, S., 2005. Modeling, mechanics and physiology of the esophagus and lower sphincter. Ph.D. thesis, The Pennsylvania State University.

Groher, M. E., 2016. Normal Swallowing in Adults. In: Dysphagia, second edi Edition. Elsevier, Ch. 5, pp. 19-40. 
Hadde, E., 2017. Understanding the Rheological Parameters of Thickened Fluids for Dysphagia Sufferers. Ph.D. thesis, The University of Queensland.

Hamlet, S., Faull, J., Klein, B., Aref, A., Fontanesi, J., Stachler, R., Shamsa, F., Jones, L., Simpson, M., 1997. Mastication and swallowing in patients with postirradiation xerostomia. International Journal of Radiation Oncology Biology Physics 37 (4), 789-796.

Hanson, B., 2016. A review of diet standardization and bolus rheology in the management of dysphagia. Current opinion in otolaryngology \& head and neck surgery, 183-190.

Harrison, S. M., Cleary, P. W., 2014. Towards modelling of fluid flow and food breakage by the teeth in the oral cavity using smoothed particle hydrodynamics (SPH). European Food Research and Technology 238 (2), 185-215.

Harting, J., Frijters, S., Ramaioli, M., Robinson, M., Wolf, D. E., Luding, S., 2014. Recent advances in the simulation of particle-laden flows. European Physical Journal: Special Topics 223 (11), 2253-2267.

Hasegawa, A., Otoguro, A., Kumagai, H., Nakazawa, F., 2005. Velocity of Swallowed Gel Food in the Pharynx by Ultrasonic Method. Nippon Shokuhin Kagaku Kogaku Kaishi 52 (10), 441-447.

Haward, S. J., Odell, J. A., Berry, M., Hall, T., 2011. Extensional rheology of human saliva. Rheologica Acta 50 (11-12), 869-879.

Hayoun, P., Engmann, J., Mowlavi, S., Le Reverend, B., Burbidge, A., Ramaioli, M., 2015. A model experiment to understand the oral phase of swallowing of Newtonian liquids. Journal of Biomechanics 48 (14), 3922-3928.

Ho, A., Affoo, R., Rogus-Pulia, N., Nicosia, M., Inamoto, Y., Saitoh, E., Green, S., Fels, S., 2017. Inferring the effects of saliva on liquid bolus flow using computer simulation. Computers in Biology and Medicine 89, 304-313.

Ho, A. K., Tsou, L., Green, S., Fels, S., 2014. A 3D swallowing simulation using smoothed particle hydrodynamics. Computer Methods in Biomechanics and Biomedical Engineering: Imaging \& Visualization 2 (4), 237-244.

Hofe, R., Moore, R. K., 2008. Towards an investigation of speech energetics using 'AnTon': an animatronic model of a human tongue and vocal tract.

1185 Connection Science 20 (4), 319-336.

Hughes, J., Culha, U., Giardina, F., Günther, F., Rosendo, A., 2016. Soft Manipulators and Grippers: A Review. Frontiers in Robotics and AI 3 (November), $1-12$.

Humbert, I. A., German, R. Z., 2013. New Directions for Understanding Neural Control in Swallowing: The Potential and Promise of Motor Learning. Dysphagia 28 (1), 1-10. 
Inamoto, Y., Fujii, N., Saitoh, E., Baba, M., Okada, S., Katada, K., Ozeki, Y., Kanamori, D., Palmer, J. B., 2011. Evaluation of swallowing using 320detector-row multislice CT.Part II: Kinematic analysis of laryngeal closure during normal swallowing. Dysphagia 26 (3), 209-217.

Jafari, S., Prince, R. A., Kim, D. Y., Paydarfar, D., 2003. Sensory regulation of swallowing and airway protection: A role for the internal superior laryngeal nerve in humans. Journal of Physiology 550 (1), 287-304.

Jimenez Lozano, J. N., 2009. Peristaltic Flow with Application to Ureteral Biomechanics. Ph.D. thesis, University of Notre Dame.

Kairaitis, K., 2010. Is the pharynx a muscular hydrostat? Medical Hypotheses 74 (3), 590-595.

Kamiya, T., Toyama, Y., Michiwaki, Y., Kikuchi, T., 2013. Development of a numerical simulator of human swallowing using a particle method (part 1. Preliminary evaluation of the possibility of numerical simulation using the MPS method). Annual International Conference of the IEEE Engineering in Medicine and Biology Society 2013, 4454-4457.

Kikuchi, T., Michiwaki, Y., Kamiya, T., Toyama, Y., Tamai, T., Koshizuka, S., 2015. Human swallowing simulation based on videofluorography images using Hamiltonian MPS method. Computational Particle Mechanics 2 (3), 247-260.

Kikuchi, T., Michiwaki, Y., Koshizuka, S., Kamiya, T., Toyama, Y., 2017. Numerical simulation of interaction between organs and food bolus during swallowing and aspiration. Computers in Biology and Medicine 80 (August 2016), 114-123.

1215 Kirkness, J. P., Eastwood, P. R., Szollosi, I., Platt, P. R., Wheatley, J. R., Amis, T. C., Hillman, D. R., 2003. Effect of surface tension of mucosal lining liquid on upper airway mechanics in anesthetized humans. Journal of applied physiology (Bethesda, Md. : 1985) 95 (1), 357-363.

Koç, H., Vinyard, C. J., Essick, G. K., Foegeding, E. A., 2013. Food oral processing: conversion of food structure to textural perception. Annual Review of Food Science and Technology 4, 237-266.

Koshizuka, S., 2005. Moving Particle Semi-Implicit (MPS) Method - A Particle Method for Fluid and Solid Dynamics. IACM Expressions 18, 4-9.

Kou, W., Pandolfino, J. E., Kahrilas, P. J., Patankar, N. A., 2015. Simulation studies of circular muscle contraction, longitudinal muscle shortening, and their coordination in esophageal transport. American journal of physiology. Gastrointestinal and liver physiology 309 (4), G238-47.

Kou, W., Pandolfino, J. E., Kahrilas, P. J., Patankar, N. A., 2017. Simulation studies of the role of esophageal mucosa in bolus transport. Biomechanics and Modeling in Mechanobiology 16 (3), 1001-1009. 
Laguna, L., Hetherington, M. M., Chen, J., Artigas, G., Sarkar, A., 2016. Measuring eating capability, liking and difficulty perception of older adults: A textural consideration. Food Quality and Preference 53, 47-56.

Laguna, L., Sarkar, A., 2016. Influence of mixed gel structuring with different degrees of matrix inhomogeneity on oral residence time. Food Hydrocolloids 61, 286-299.

Laguna, L., Sarkar, A., 2017a. Oral tribology: update on the relevance to study astringency in wines. Tribology - Materials, Surfaces \& Interfaces 11 (2), 116123.

1240 Laguna, L., Sarkar, A., 2017b. Oral tribology: update on the relevance to study astringency in wines. Tribology - Materials, Surfaces and Interfaces 11 (2), $116-123$.

Leonard, R., Kendall, K., 2008. Dysphagia assessment and treatment planning: a team approach. Plural Publishing.

1245 Levine, M. S., Rubesin, S. E., 2017. History and Evolution of the Barium Swallow for Evaluation of the Pharynx and Esophagus. Dysphagia 32 (1), 55-72.

Li, M., Brasseur, J. G., 1993. Non-steady peristaltic transport in finite-length tubes. Journal of Fluid Mechanics 248 (-1), 129.

Lloyd, J. E., Stavness, I., Fels, S., 2012. ArtiSynth: A Fast Interactive Biomechanical Modeling Toolkit Combining Multibody and Finite Element Simulation. Soft Tissue Biomechanical Modeling for Computer Assisted Surgery, 355-394.

Logemann, J. A., 1988. Dysphagia in movement disorders. Adv.Neurol. 49, 307316.

1255 Lu, X., Xu, W., Li, X., 2017. A Soft Robotic Tongue-Mechatronic Design and Surface Reconstruction. IEEE/ASME Transactions on Mechatronics 22 (5), 2102-2110.

Mackley, M. R., Tock, C., Anthony, R., Butler, S. a., Chapman, G., Vadillo, D. C., 2013. The rheology and processing behavior of starch and gum-based $1260 \quad$ dysphagia thickeners. Journal of Rheology 57 (6), 1533.

Marconati, M., Lopez, F. L., , Gul, M. O., Tuleu, C., Ramaioli, M., 2018, Submitted. In vitro and sensory tests to design easy-to-swallow multiparticulate formulations.

Marconati, M., Raut, S., Burbidge, A., Engmann, J., Ramaioli, M., 2017a. An

1265 in vitro experiment to simulate how easy tablets are to swallow. International Journal of Pharmaceutics 535 (1-2), 27-37. 
Marconati, M., Raut, S., Charkhi, F., Burbidge, A., Engmann, J., Ramaioli, M., 2017b. A model experiment to study swallowing of spherical and elongated particles. EPJ Web of Conferences 140, 09018.

Martín-Alfonso, J. E., Cuadri, A. A., Berta, M., Stading, M., 2018. Relation between concentration and shear-extensional rheology properties of xanthan and guar gum solutions. Carbohydrate Polymers 181, 63-70.

Mathieu, V., de Loubens, C., Thomas, C., Panouillé, M., Magnin, A., Souchon, I., 2018. An experimental model to investigate the biomechanical determinants of pharyngeal mucosa coating during swallowing. Journal of biomechanics $72,144-151$.

Matsuo, K., Palmer, J. B., 2016. Video fluoroscopic techniques for the study of oral food processing. Current Opinion in Food Science 9, 1-10.

Matta, Z., Chambers IV, E., Garcia, J. M., Helverson, J. M., 2006. Sensory Characteristics of Beverages Prepared with Commercial Thickeners Used for Dysphagia Diets. Journal of the American Dietetic Association 106 (7), 10491054.

Meng, Y., Rao, M., Datta, A., 2005. Computer Simulation of the Pharyngeal Bolus Transport of Newtonian and Non-Newtonian Fluids. Food and Bioproducts Processing 83 (4), 297-305.

Meyer, G. W., Austin, R. M., Brady, C. E., Castell, D. O., 1986. Muscle anatomy of the human esophagus. Journal of Clinical Gastroenterology 8 (2), 131-134.

Minizuma, H., Sonomura, M., Shimokasa, K., Ogoshi, H., Nakamura, S., Tayama, N., 2009. Numerical modeling and simulation on the swallowing 1290 of jelly. Journal of Texture Studies 40 (4), 406-426.

Misra, J., Pandey, S., 2001. A mathematical model for oesophageal swallowing of a food-bolus. Mathematical and Computer Modelling 33 (8-9), 997-1009.

Misra, J. C., Maiti, S., 2012. Peristaltic transport of rheological fluid: model for movement of food bolus through esophagus. Applied Mathematics and $1295 \quad$ Mechanics 33 (3), 315-332.

Mittal, R. K., 2012. Motor Function of the Pharynx, the Esophagus, and Its Sphincters. In: Physiology of the Gastrointestinal Tract. Vol. 1. Morgan \& Claypool Life Sciences, pp. 919-950.

Molfenter, S. M., Steele, C. M., 2012. Temporal variability in the deglutition literature. Dysphagia 27 (2), 162-177.

Mosca, A. C., Chen, J., 2016. Food oral management: Physiology and objective assessment.

Mosca, A. C., Chen, J., 2017. Food-saliva interactions: Mechanisms and implications. Trends in Food Science \& Technology 66, 125-134. 
Mossaz, S., Jay, P., Magnin, A., Panouillé, M., Saint-Eve, A., Déléris, I., Juteau, A., Souchon, I., 2010. Measuring and predicting the spreading of dairy products in the mouth: Sensory, instrumental and modelling approaches. Food Hydrocolloids 24 (8), 681-688.

Mowlavi, S., Engmann, J., Burbidge, A., Lloyd, R., Hayoun, P., Le Reverend, B., Ramaioli, M., 2016. In vivo observations and in vitro experiments on the oral phase of swallowing of Newtonian and shear-thinning liquids. Journal of Biomechanics 49 (16), 3788-3795.

Naumann, A., Dennis, J. E., Awadallah, A., Carrino, D. A., Mansour, J. M., Kastenbauer, E., Caplan, A. I., 2002. Immunochemical and Mechanical Characterization of Cartilage Subtypes in Rabbit. The Journal of Histochemistry \& Cytochemistry 50 (8), 1049-1058.

Neyraud, E., Palicki, O., Schwartz, C., Nicklaus, S., Feron, G., 2012. Variability of human saliva composition: Possible relationships with fat perception and liking. Archives of Oral Biology 57 (5), 556-566.

Ng, G. C. F., Gray-Stuart, E. M., Morgenstern, M. P., Jones, J. R., Grigg, N. P., Bronlund, J. E., 2017. The slip extrusion test: A novel method to characterise bolus properties. Journal of Texture Studies 48 (4), 294-301.

Nicosia, M. A., 2007. A planar finite element model of bolus containment in the oral cavity. Computers in Biology and Medicine 37 (10), 1472-1478.

325 Nicosia, M. A., 2013. Theoretical Estimation of Shear Rate during the Oral Phase of Swallowing: Effect of Partial Slip. Journal of Texture Studies 44 (2), $132-139$.

Nishinari, K., Takemasa, M., Su, L., Michiwaki, Y., Mizunuma, H., Ogoshi, H., 2011. Effect of shear thinning on aspiration - Toward making solutions for judging the risk of aspiration. Food Hydrocolloids 25 (7), 1737-1743.

Noh, Y., Segawa, M., Sato, K., Chunbao Wang, Ishii, H., Solis, J., Takanishi, A., Katsumata, A., Iida, Y., 2011. Development of a robot which can simulate swallowing of food boluses with various properties for the study of rehabilitation of swallowing disorders. In: 2011 IEEE International Conference on Robotics and Automation. IEEE, pp. 4676-4681.

Noh, Y., Wang, C., Tokumoto, M., Jorge, S., Ishii, H., Takanishi, A., Kazuyuki, H., Shoji, S., 2012a. Development of Airway Management training system WKA-4: Provide useful feedback of trainee performance to trainee during Airway Management. 2012 ICME International Conference on Complex Medical Engineering, CME 2012 Proceedings, 423-428.

Noh, Y., Wang, C., Tokumoto, M., Matsuoka, Y., Chihara, T., Ishii, H., Takanishi, A., Takayama, T., Shoji, S., 2012b. Development of the airway Management Training System WKA-5: Improvement of mechanical designs for highfidelity patient simulation. 2012 IEEE International Conference on Robotics and Biomimetics, ROBIO 2012 - Conference Digest, 1224-1229. 
Nystrom, M., Qazi, W. M., Bolow, M., Ekberg, O., Stading, M., Nyström, M., Qazi, W. M., Bülow, M., Ekberg, O., Stading, M., 2015. Effects of rheological factors on perceived ease of swallowing. Applied Rheology 25 (6), 40-48.

Osada, T., Kamiya, T., Toyama, Y., Jinno, N., Kikuchi, T., Michiwaki, Y., 2014. Numerical analyses of food bolus velocity and force on epiglottis during swallowing using 3D swallowing simulator "Swallow Vision". In: 11th World Congress on Computational Mechanics, WCCM 2014. pp. 2-6.

Panouillé, M., Saint-Eve, A., Souchon, I., 2016. Instrumental methods for bolus characterization during oral processing to understand food perceptions. Current Opinion in Food Science 9, 42-49.

Paterson, W. G., 2006. Esophageal peristalsis. GI Motility online, Published online: 16 May 2006; — doi:10.1038/gimo13.

Peyron, M.-A. A., Woda, A., 2016. An update about artificial mastication. Current Opinion in Food Science 9, 21-28.

Popa Nita, S., Murith, M., Chisholm, H., Engmann, J., 2013. Matching the Rheological Properties of Videofluoroscopic Contrast Agents and Thickened Liquid Prescriptions. Dysphagia 28 (2), 245-252.

Pradal, C., Stokes, J. R., 2016. Oral tribology: Bridging the gap between physical measurements and sensory experience.

Pramanik, R., Osailan, S. M., Challacombe, S. J., Urquhart, D., Proctor, G. B., 2010. Protein and mucin retention on oral mucosal surfaces in dry mouth patients. European Journal of Oral Sciences 118 (3), 245-253.

Preciado-Méndez, M., Salinas-Vázquez, M., Vicente, W., Brito-de la Fuente, E., Ascanio, G., 2017. Numerical analysis of extensional flow through the pharyngeal duct. Journal of Physics: Conference Series 790 (1), 012025.

Prinz, J. F., Lucas, P. W., 1995. Swallow threshold in human mastication. Archives of Oral Biology 40 (5), 401-403.

Qazi, W. M., Stading, M., 2017. In Vitro Models for Simulating Swallowing. In: Medical Radiology. Springer Berlin Heidelberg, Berlin, Heidelberg, pp. 1-14.

Raguin, T., Carvalho, J., Riehm, S., Takeda, C., Dupret-Bories, A., 2016. Method for dealing with severe aspiration using a new concept of intralaryngeal prosthesis: A case report. Head and Neck 38 (10), E2504-E2507.

Ranc, H., Elkhyat, A., Servais, C., Mac-Mary, S., Launay, B., Humbert, P., 2006. Friction coefficient and wettability of oral mucosal tissue: Changes induced 1380 by a salivary layer. Colloids and Surfaces A: Physicochemical and Engineering Aspects 276 (1-3), 155-161. 
Redfearn, A., Hanson, B., 2018. A Mechanical Simulator of Tongue-Palate Compression to Investigate the Oral Flow of Non-Newtonian Fluids. IEEE/ASME Transactions on Mechatronics 23 (2), 958-965.

Stavness, I., Lloyd, J. E., Fels, S., 2012. Automatic prediction of tongue muscle activations using a finite element model. Journal of Biomechanics 45 (16), $2841-2848$.

Steele, C. M., 2015. The Blind Scientists and the Elephant of Swallowing: A Review of Instrumental Perspectives on Swallowing Physiology. Journal of Texture Studies 46 (3), 122-137.

Steele, C. M., Alsanei, W. A., Ayanikalath, S., Barbon, C. E. A., Chen, J., Cichero, J. A. Y., Coutts, K., Dantas, R. O., Duivestein, J., Giosa, L., Hanson, B., Lam, P., Lecko, C., Leigh, C., Nagy, A., Namasivayam, A. M., Nascimento, 

Texture and Liquid Consistency Modification on Swallowing Physiology and Function: A Systematic Review. Dysphagia 30 (1), 2-26.

Steele, C. M., Miller, A. J., 2010. Sensory input pathways and mechanisms in swallowing: A review.

Steele, C. M., Molfenter, S. M., Péladeau-Pigeon, M., Polacco, R. C., Yee, C., 2014. Variations in Tongue-Palate Swallowing Pressures When Swallowing Xanthan Gum-Thickened Liquids. Dysphagia 29 (6), 678-684.

Stokes, J. R., 2012a. Oral Rheology. In: Wiley (Ed.), Food Oral Processing. No. February. Wiley-Blackwell, Oxford, UK, Ch. 11, pp. 225-263.

Stokes, J. R., 2012b. 'Oral' Tribology. In: Food Oral Processing. WileyBlackwell, Oxford, UK, pp. 265-287.

Sulica, L., Hembree, A., Blitzer, A., 2002. Swallowing and sensation: Evaluation of deglutition in the anesthetized larynx. Annals of Otology, Rhinology and Laryngology 111 (4), 291-294.

Sworn, G., 2017. Rheology Modifiers for the Management of Dysphagia. Springer Japan, Ch. 10, pp. 233-263.

Tannock, I. F., Ph, D., Hickman, J. A., Sc, D., 2017. Implantation of an Artificial Larynx after Total Laryngectomy. New England Journal of Medicine 376 (1), 95-97.

Tripathi, D., 2011. A mathematical model for the movement of food bolus of varying viscosities through the esophagus. Acta Astronautica 69 (7-8), 429439.

Tripathi, D., Pandey, S., Bég, O. A., 2013. Mathematical modelling of heat transfer effects on swallowing dynamics of viscoelastic food bolus through the human oesophagus. International Journal of Thermal Sciences 70, 41-53.

Vilardell, N., Rofes, L., Arreola, V., Speyer, R., Clavé, P., 2016. A Comparative Study Between Modified Starch and Xanthan Gum Thickeners in Post-Stroke Oropharyngeal Dysphagia. Dysphagia 31 (2), 169-179.

Violeau, D., Rogers, B. D., 2016. Smoothed particle hydrodynamics (SPH) for 1450 free-surface flows: past, present and future. Journal of Hydraulic Research $54(1), 1-26$.

Wang, X., Chen, J., 2017. Food oral processing: Recent developments and challenges. Current Opinion in Colloid \& Interface Science 28, 22-30.

Watanabe, M., Sekine, K., Hori, Y., Shiraishi, Y., Maeda, T., Honma, D., ${ }_{1455}$ Miyata, G., Saijo, Y., Yambe, T., 2005. Artificial Esophagus With Peristaltic Movement. ASAIO Journal 51 (2), 158-161. 
Watanabe, S., Dawes, C., 1990. Salivary Flow Rates and Salivary Film Thickness in Five-year-old Children. Journal of Dental Research 69 (5), 1150-1153.

Weickenmeier, J., Jabareen, M., Le Révérend, B. J. D., Ramaioli, M., Mazza, E., 2017. Experimental and Numerical Characterization of the Mechanical Masseter Muscle Response During Biting. Journal of Biomechanical Engineering 139 (12), 121007.

Wong, S. M., Domangue, R. J., Fels, S., Ludlow, C. L., 2017. Evidence that an internal schema adapts swallowing to upper airway requirements. Journal of Physiology 595 (5), 1793-1814.

Zhang, S., Olthoff, A., Frahm, J., 2012. Real-time magnetic resonance imaging of normal swallowing. Journal of Magnetic Resonance Imaging 35 (6), 13721379 .

Zhu, M. Z., Xu, W. L., Member, S., Cheng, L. K., 2016. Esophageal Peristaltic 1470 Control of a Soft-bodied Swallowing Robot by Central Pattern Generator. IEEE/ASME Transactions on Mechatronics 4435 (c), 1-8. 